\title{
NAVIGATING PARADOXICAL TENSIONS THROUGH THE INTERPLAY OF TEMPORAL STRUCTURES
}

\author{
Jack Fraser ${ }^{1}$, Shaz Ansari², and Majken Shultz ${ }^{3}$
}

\begin{abstract}
Organizations at the boundary of two fields are often required to meet contradictory but interrelated demands. While transcendence - accepting both sets of demands as necessary and complementary - has been shown to be an important response to such paradoxes, achieving it places significant cognitive and behavioural strain on managers. Despite the importance of 'both/and' approaches for the survival of pluralistic organizations, we still know little about the practices that managers resort to when initial efforts to achieve transcendence break down. Through a longitudinal study of a jointventure created by two parent companies in distinct fields, we demonstrate that managers can address otherwise insurmountable paradoxical tensions through an emphasis on the interplay of their temporal structures. By deconstructing competing demands into their respective temporal qualities of temporal depth-defined as the span into the past and future that they typically consider-and temporal horizons - measured by the frequency of milestones within this span - managers can process paradoxical demands in novel ways. Through a process of temporal reflexivity, managers on both sides were able to negotiate a new, shared temporal depth that accommodated the temporal horizons of both sides. We show that this process enabled managers to achieve a form of quasi-transcendence, in which opposing demands were accommodated though not fully accepted as necessary. This allowed the organization to satisfy competing demands where conventional approaches to paradoxes could not be sustained.
\end{abstract}

\footnotetext{
${ }^{1}$ Saïd Business School, University of Oxford

2 Judge Business School, University of Cambridge

${ }^{3}$ Copenhagen Business School
} 
"Time flows in the same way for all human beings; every human being flows through time in a different way."

- Yasunari Kawabata

For many firms, the ability to cope with multiple, contradictory demands is not only important for sustained performance, but for maintaining the very existence of the organization. For pluralist organizations - those comprised of multiple actors pursuing distinct goals - the presence of competing demands is a natural consequence of their form (Hardy, 1991; Kraatz and Block, 2008). In these contexts, opposing demands are both persistent and prevalent, existing in 'constant dynamic tension' (Denis et al., 2001., 809). Research exploring how managers cope with the tensions that surface between these competing demands (Pache and Santos, 2010; Jay, 2013) have begun to draw on a paradox lens (Jay, 2013; Smith and Tracey, 2016). This emphasizes the interdependence of the opposing demands in these contexts, such that addressing one demand makes the opposing demand more imperative (Farjoun, 2017; Smith and Lewis, 2011). For example, managers may face competing pressures to explore new product development and exploit existing capabilities (Andriopoulos and Lewis, 2009; Smith and Tushman, 2005), or between the need to compete and cooperate with other firms (De Rond and Bouchiki, 2004; Rosenkopf and Tushman, 1998). In these contexts, trading off one demand in favour of another would ultimately be a 'pyrrhic victory' (Reineke and Ansari, 2015: 639), which would damage the organization's long-term prospects. The challenge, from a paradox lens, is to move from an understanding of competing demands emanating from fields as "either/or" trade-offs and instead position them as opportunities for "both/and" solutions (Gibson and Birkinshaw, 2004; Lewis, 2000; Smith et al., 2017). Transcendence - in which agents understand both poles of the paradox to be necessary and complementary (Jarzabkowski, Lê, and Van de Ven, 2013; Lewis, 2000; Poole and Van de Ven, 1989; Smith and Tracey, 2016) - may be necessary in contexts defined by organizational pluralism. In these contexts, jointly addressing contradictory demands is a 'minimum requirement for bare survival' (Kraatz and Block, 2008: 5).

While valuable, such an approach is cognitively demanding and difficult to achieve in practice (Lüscher and Lewis, 2008; Smith and Lewis, 2011). Accepting such demands as necessary and interrelated 'intensifies experiences of tension, challenging actors' cognitive limits' 
(Smith and Lewis, 2011: 395). Consequently, such paradoxical inquiry has been understood even by its proponents - as 'precarious' (Lüscher and Lewis, 2008: 237). Understanding the mechanisms through which managers do manage to navigate competing expectations is especially pertinent in these pluralistic contexts, where jointly satisfying multiple demands is necessary for the continued existence of the firm (Kraatz and Block, 2008).

We argue that recent research exploring the interplay of oppositional temporal structures can provide insights into the processes that managers use to navigate paradoxical demands. Temporal structures are socially constructed understandings of time (Grangvist and Gustafsson, 2016; Orlikowski and Yates, 2002) that underpin practices (Rowell et al., 2017) and influence how managers interpret their environment (Granqvist and Gustafsson, 2016; Oborn and Barrett, 2020). Recent research has suggested that the interplay of these structures can help managers bridge gaps between opposing practices and demands (Oborn and Barrett, 2020; Schultz and Hernes, 2019; Reineke and Ansari, 2015). Schultz and Hernes (2019) show how recombining the constructs of temporal depth and temporal horizons influence the interplay of strategy and identity. Reineke and Ansari (2015) explore how, through a process of reflexivity and negotiation, managers at Fairtrade International were able to bridge the deadline-oriented 'clock time' with event-oriented 'process time' to operate with both a market and development model.

While the interplay of temporal structures may help bridge competing practices and demands, the application of such an approach to paradoxical tensions driven by operating across two distinct fields raises several issues. The underlying temporal structures of opposing demands may not be immediately apparent to managers. Rather, managers face surface-level tensions (Schad and Bansal, 2019) between competing dualities of identities, business models, and strategic goals (Greenwood et al., 2011; Kraatz and Block, 2008; Jay, 2013). There is a lack of empirical research into the process through which these temporal structures become both salient to managers and the primary mechanism through which they process paradoxical tensions. Understanding the processes involved in this kind of 'interpretive shift' (Staudenmayer et al., 2002) sheds light on how a temporal structuring approach can address paradoxical tensions.

In a similar vein, the role that the interplay of temporal structures has on managerial understandings of paradox is not clear. While research supports the notion that structural interplay can allow managers to work with competing temporal structures to achieve a form 
of 'temporal ambidexterity' (Slawinski and Bansal, 2015: 544), it is not clear whether or when this amounts to a shift in managerial understanding that the poles of the paradox are 'inextricably linked and mutually influential' (Chen and Miller, 2011, 13). Further empirical research is needed to understand whether such structural interplay can influence how individuals understand paradoxical demands.

To explore these issues, we conduct an inductive, longitudinal case study of Creative Hub - a joint venture formed by two parent companies in separate sectors: the banking and advertising industries. Through participant observation, depth interviews, and content analysis, we explore the organizational complexity in this structure, and the paradoxical demands that arise as a result. Initial efforts to process these paradoxical tensions through a transcendent approach proved difficult to maintain. During an extended period of sensemaking, the differences in the temporal structures of each pole became salient, with marked differences in temporal depth (the distance into the past and future that managers normally consider) and temporal horizons (the intervals at which agents measure progress). A form of temporal reflexivity emerged, in which managers acknowledged and interrogated their temporal assumptions. In the latter stages of fieldwork, managers engaged in a process of renegotiating a shared temporal depth that accommodated the temporal horizons of both sides. This mid-length, defined temporal depth created a common ground to discuss and justify their respective temporal horizons.

While managers did not come to believe that the objectives of the opposing paradigm were necessary or complementary to their own objectives, they were able to accommodate them within the revised temporal depth. We argue that this quasi-transcendence - in which opposing demands are accommodated though not fully accepted as necessary - allowed the organization to satisfy competing demands in a manner that was more sustainable than traditional approaches to transcendence. We argue that such an approach was possible through a focus on the interplay of temporal structures. In breaking down opposing paradigms into their distinct depth and horizons, managers were able to negotiate a more nuanced interplay that was not possible when the competing demands were considered as binary forces. This allowed managers to move beyond the breakdowns that defined the early formation of the organization. 


\section{Theoretical Exposition}

\subsection{Organizational pluralism and paradoxical demands}

Ventures created through a collaborative agreement from two or more parent companies often embody a high degree of pluralism as divergent goals and expectations exist within an intended collaboration (Brès et al.,2018). In collaborative arrangements such as joint ventures and hybrid organizations, the organization becomes a setting where 'a multiplicity of actors and groups pursue varying goals' (Denis et al., 2001, 809). In these circumstances, competing objectives and demands are continuously at play within the organisation, such that 'reconciliation by fiat is not an option, these opposing forces are in constant dynamic tension' (2001, 809). Endogenous to the organization, managers have to navigate these competing demands as a minimum standard for survival (Greenwood et al., 2011; Kraatz and Block, 2008). This pluralism of demands places significant strain on organizations, as satisfying demands from one coalition can inhibit the organization's ability to meet those of the other (Hardy, 1991; Kraatz and Block, 2008; Pache and Santos, 2010). While early approaches to these competing demands drew largely on an institutional theory - conceptualising such competing demands as emanating from competing institutional logics (Greenwood et al, 2011) - recent work has called for greater emphasis on a paradox lens (Jay, 2013; Smith and Tracey, 2016). A paradox approach emphasises the interrelation of such contradictory demands as an inherent facet of organizing (Schad and Bansal, 2019). Paradox emphasises not only the contradiction in pluralism, but also the dyadic interdependence of opposing demands, such that addressing one demand strengthens its opposition (Clegg et al, 2002; Farjoun, 2017; Smith and Lewis, 2011).

Emphasising a social constructivist ontology, much of the paradox literature has focused on the ability of managers to treat contradictory demands not as "either/or" trade-offs, but rather as opportunities for "both/and" solutions (Gibson and Birkinshaw, 2004; Lewis, 2000; Smith et al., 2017). Transcendence - this ability to treat both sides of the paradox as necessary and complementary (Jarzabkowski, Lê, and Van de Ven, 2013; Lewis, 2000) - has been shown to allow managers to overcome the conflict associated with opposing demands (Farjoun, 2010). By 'moving to a higher plane of understanding' (Jarzabkowski, Lê, and Van de Ven, 2013: 249) managers can treat competing demands as jointly necessary and simultaneously address both poles of the paradox (Bednarek et al., 2016). 
The literature exploring the mechanisms that underpin a transcendence approach largely draw on socio-cognitive traditions - emphasising the role of framing (Jay, 2013; Smith and Tushman, 2005), sensemaking (Lüscher and Lewis, 2008), and sensegiving (Bednarek et al., 2016). In doing so, this work gives managerial cognition a central role. Hahn et al (2014) distinguish between a business case frame and a paradox frame. While the former highlights economic objectives, the latter underpins a more ambivalent perspective, allowing managers to consider "more comprehensive responses" (2014: 465) to sustainability challenges. In their study of the cognitive microfoundations of responses to paradoxical demands, Miron-Spektor et al (2018) identify a 'paradox mindset' - the ability to be 'accepting of and energised by tensions' (2018: 26) - as central to managers' ability to navigate competing demands.

A parallel stream of research has explored the collective sensemaking approach that takes place amongst managers. Lüscher and Lewis (2008) explore how reflection and collective sensemaking allows managers to view contradictory demands as inherently related. Building on earlier work by Cameron and Quinn (1988) and Poole and Van de Ven (1989), Lüscher and Lewis (2008) propose that a 'paradox lens' (2008: 222) allows managers to 'consider other perspectives, alter their assumptions, and explore issues in fundamentally different ways' (2008: 234). This use of a paradox lens in the sensemaking process moves the question away from 'either/or' dilemmas to more nuanced questions about how to accommodate both demands, allowing for sufficient workable certainty to progress.

\subsection{Limits, Complexity, and Alternate Lenses}

While the pursuit of 'both/ and' approaches could help mangers navigate the contradictory demands inherent in pluralist organizations (Smith and Tracey, 2016), such an approach is cognitively demanding and difficult to sustain in practice (Lüscher and Lewis, 2008; Smith and Lewis, 2011). Smith and Lewis (2011) argue that attention to interrelated yet opposing demands 'intensifies experiences of tension, challenging actors' cognitive limits' (2011: 395). Embracing paradoxical tensions tests managers' cognitive capabilities and requires a high degree of emotional equanimity (2011: 391). Leana and Barry (2000) propose that unique managerial capabilities - including openness to new experiences and a tolerance for ambiguity - are crucial factors in managerial attempts to cope with competing demands. This is supported by earlier findings in the cognitive science literature that shows that individuals prioritise consistency (Cialdini, Trost, and Newsom, 1995) and have a tendency to respond to contradiction with emotional anxiety (Schneider, 1990) and defensive behaviour (Vince and 
Broussine, 1996). In a similar vein, Lüscher and Lewis (2008) note that paradox frames are precarious, due to a managerial tendency to revert to old approaches in the face of ambiguity.

Left unresolved, irreconcilable divides between competing demands can lead to breakdowns in understanding (Ybema, 2010), resulting in conflict (Amason, 1996; Golden-Biddle and Rao, 1997; Hatch and Ehrlich, 1993; Lewis, 2000; Maitlis and Sonenshein, 2010; Pache and Santos, 2010). The consequences of breakdowns in addressing competing demands are especially pertinent for organizations such as joint ventures, where attending to demands emanating from two parent organizations is necessary for the survival of the organization (Inkpen and Currall, 2004; Jay, 2013; Kaatz and Block, 2008). In contexts defined by such pluralism, how do managers accommodate polarised demands when efforts to recognise each pole as 'necessary and complimentary' (Bednarek et al., 2016) fail to take hold?

To address this, we build on recent work calling for a movement away from visible, dualistic tensions, and a greater focus on the complex ontology of paradoxes (Schad and Bansal, 2019). Tsoukas (2017) emphasises the importance of moving beyond simplified dualisms to acknowledge the complexity of understandings, processes and relationships in pluralist organizations. Schad and Bansal (2019) argue that 'zooming in' would result in a richer understanding of paradoxical tensions and the steps taken by managers to navigate them. Nicolini, (2009) proposes that a 'zooming in' approach is concerned less with increasing detail, but rather 'the switching of theoretical lenses to allow for new aspects of the phenomenon to come to the fore' $(2009,18)$. In the following section we propose switching theoretical lenses to elevate the role of temporality. Specifically, we argue that focusing on the role of temporal structures and their interplay (Reineke and Ansari, 2015; Schultz and Hernes, 2019) can uncover new approaches to managing paradoxical demands.

\subsection{Temporal Structures}

Recent research within the temporality literature has emphasised the interplay of different temporal structures - socially constructed understandings of time that influence how managers make sense of and coordinate practices (Grangvist and Gustafsson, 2016; Kunish et al., 2017; Orlikowski and Yates, 2002) - in navigating intra-organizational tensions. Temporal structures can differentiate the urgency understood by managers (Shipp and Cole, 2015; Chen and Nadkarni, 2017), the degree of attention paid to the past, present or future (Kaplan and Orlikowski, 2013; Zimbardo and Boyd, 1999), or the distances into the past or future that 
managers consider (Bluedorn and Standifer, 2006; Kunish et al., 2017). These temporal structures underpin practices (Rowell et al., 2017), influencing how managers coordinate patterns of working (Granqvist and Gustafsson, 2016; Orlikowski and Yates, 2002).

In their study of the Carlsberg Group, Schultz and Hernes (2019) explore the interplay of strategy and identity by deconstructing their differing temporalities into the structures of temporal depth and temporal horizons, and exploring the effect that different combinations of these components have on the interaction between strategy and identity. Their work builds on Bluedorn's (2002) conceptualization of temporal depth - as 'the temporal distances into the past and future that individuals and collectives typically consider' $(2002,114)$. This depth is distinct from the notion of temporal horizons - which mark the events or moments that segment this overall depth. By distinguishing between different forms of temporal structures, Schultz and Hernes (2019) explore how different combinations of these temporal constructs influence the interplay between the macro-structures of strategy and identity. One implication of sustained temporal interplay is that strategy becomes more meaningful, while identity becomes more actionable to the involved actors. In their study of temporal perspectives in response to climate change, Slawinski and Bansal (2015) found that management teams who were able to integrate broader temporal perspectives with longer time horizons were able to develop more comprehensive responses to climate change than the companies that polarized the differences between short-and long-term horizons.

Some authors have emphasised the collective processes that facilitate the interplay between different temporal perspectives. Reineke and Ansari (2015) explain how Fairtrade International managed to bridge deadline-oriented 'clock time' and event-oriented 'process time' structures through a process of contestation and negotiation. Their work builds on the notion of temporal reflexivity - 'the human potential for reinforcing and altering temporal structures' (Orlikowski and Yates, 2002: 698) - to argue that contradictory temporal structures can be reshaped and aligned. Ultimately, this resulted in a 'mutual appreciation' $(2015,636)$ of the temporal demands of each side.

Adjacent literature has emphasised the cognitive and behavioural capabilities of individuals as key to facilitating sustained temporal interplay. Chen et al. (2019) draw on the interplay of different temporal structures to understand how mangers cope with the competing demands in the pursuit of organizational ambidexterity. This work builds on the notion that longer temporal horizons direct attention to the distant future (Das, 1987; Wang and Bansal, 2012); 
while short horizons lead managers to attend to current environmental cues that prioritise more immediate results (Shipp et al., 2009; Lumpkin and Bringham, 2011). From this, Chen et al (2019) argue that a diversity of time horizons is key to achieving ambidexterity. Their work identifies the behaviours and capabilities of senior leadership teams - including effective scheduling and synchronisation - as key to maintaining multiple, often opposing time horizons $(2019,16)$.

We argue that this interplay of temporal structures provides novel routes towards understanding how managers process competing, paradoxical demands. By 'zooming in' to unpick the temporal structures of each demand, complex and nuanced interactions become possible that would not emerge if we were to focus on the surface level demands (Schad and Bansal, 2019). Our work seeks to empirically explore nature of the temporal structures that comprise competing paradoxical demands, and their interplay in addressing paradox.

\subsection{Addressing Paradox Through Temporal Structural Interplay - Emerging Issues}

The salience of temporal structures. Research that has applied a temporal lens to paradoxical tensions has predominantly focused on contexts in which managers already understand the paradoxes facing them in temporal terms. As a result, the process through which temporal structures become salient is under explored. Research has, for example, highlighted the propensity of managers to view the tensions between exploitation and exploration as one of inter-temporal choice, weighing up the demands of the near and distant future (Ancona et al., 2001; Chen et al., 2019; Mathias et al., 2017). In doing so, the demands are understood from the outset in temporal terms. Similarly, issues surrounding organizational change are often formulated by managers as an inter-temporal choice between the needs of the present and understandings of the future (Kaplan and Orlikowski, 2013). Individuals who are capable of holding multifaceted temporal perspectives are better able to navigate the tensions around organizational change (Gibson et al., 2007; Kunish et al., 2015).

While temporal structures may play a significant role in helping mangers navigate paradoxical tensions, the process through which such structures become relevant remains under explored. This is particularly significant in cases of paradoxes driven by organizational plurality, where coalitions of actors differ in varied and complex ways. In these cases, the competing demands facing managers may not initially be understood with relation to their temporal structures, but rather as competing dualities of identities, practices, and goals (Greenwood et al., 2011; Kraatz 
and Block, 2008; Jay, 2013). Navigating paradoxical demands through the interplay of their temporal structures would involve an 'interpretive shift' (Staudenmayer et al., 2002) changing the categories through which managers understand the world.

Structural Interplay and Transcendence. A related issue for researchers concerns the role that an approach focused on the interplay of temporal structures has on managerial understanding of paradoxical demands. While research has explored the processes through which managers process and accommodate multiple temporalities, it is not yet clear what impact this has on managers treatment of the 'inherent and persistent' contradictions that constitute paradox.

While research supports the notion that the interplay of different temporalities can underpin a form of 'temporal ambidexterity' (Slawinski and Bansal, 2015: 544) at the organizational level - in which the organisation can pursue both short- and long-term horizons - it is not clear whether this amounts to a recognition at the managerial level that the two poles of the paradox are 'inextricably linked and mutually influential' (Chen and Miller, 2011, 23). Similarly, while temporal structures have been shown to shape practices (Huy, 2001; Rowell et al., 2017), and direct what managers pay attention to (Oborn and Barrett, 2020); whether and how they influence individuals' understandings of paradoxical demands is less clear.

\subsection{Challenges and Considerations}

While a focus on the interplay of temporal structures is a promising pathway for researchers seeking to understand how managers process tensions between competing demands, challenges remain for paradox scholars. First, if paradoxical demands can be navigated through temporal interplay, how do these temporal structures become both salient and pertinent for managers? Secondly, what role does this interplay of temporal structures have on managers' understanding of the paradoxical demands they face?

The remainder of this paper seeks to address these issues through an inductive, longitudinal exploration of the interplay of temporal structures in the maintenance of a joint venture, an organizational form susceptible to tensions between opposing yet mutually necessary demands (Battilana and Dorado, 2010; Pache and Santos, 2010). 


\section{Methodology}

This paper is intended to "reconnect and redirect" (Lee et al., 1999: 166) two related yet often distinct research streams; that is the study of paradox and temporality. In doing so, we aim to explore the manner in which temporality influences how paradoxical tensions are processed. To achieve this, our study focused on hybrid organising through joint ventures, a setting associated with the emergence of paradoxical tensions (Battilana and Dorado, 2010; Inkpen and Currall, 2004). In keeping with the view of responses to paradox as a dynamic process (Bednarek et al., 2016; Smith and Lewis, 2011), we adopt a longitudinal, process-driven approach (Langley et al., 2013) to capture how understandings and practices develop and adapt over time.

\subsection{Case Selection and Context}

Our insights emerged from an inductive study of the formation and initial years of CreativeHub, a joint venture established by Fincorp - a multinational financial services organisation - and Commcorp - a media and communications conglomerate. The aim of the joint venture was to provide Fincorp with an in-house creative agency who could support a range of communications, design and advertising services at a lower cost and higher speed than an external agency.

This model, initially referred to as 'the Fincorp Agency' before it's branding prior to launch as CreativeHub, was a new approach for both parent companies. Fincorp had previously used external agencies for all of their branding, advertising, and communications work. These agencies would be managed by Fincorp's marketing department, who would select through a pitch process and hire agencies through a retained contract with additional payments for work that was outside the scope of the retained agreement or that took significantly more time or staff to complete. Commcorp ran a network of advertising and communications agencies throughout Europe, each retained by multiple clients on contracts that were regularly reviewed based on the quality and cost efficiency of outputs, and the creative quality of the work.

For both Fincorp and Commcorp, creating an 'internal' agency to run as a joint venture brought several benefits. For Fincorp, having a dedicated internal resource would allow work to be developed faster and at short notice. Work would be able to be tied much more strategically into the aims and goals of the marketing department through a closer working 
relationship and a shared understanding of the organization. Through greater transparency and cost control, it was believed that the cost of agency services would be dramatically reduced. For Commcorp, creating an internal agency with a multinational financial services organization created the opportunity to secure a financially stable blue-chip client, and provide a stable, long term revenue stream in a highly volatile market. It was also hoped that a closer client-agency working relationship would help the agency produce more compelling and powerful creative work.

The new entity was created through a joint-ownership agreement with each parent company owning a 50 per cent stake. The organization was launched in Q4 2016 following 6 months of discussions and was initially comprised of 12 executives transferred from Commcorp and a further 10 individuals seconded from Fincorp's marketing function, though this number changed substantially during our fieldwork. While CreativeHub was registered as a standalone company, it's staff remained on either Fincorp or Commcorp contracts, and were seconded to CreativeHub who would reimburse the parent companies for staff wages. It was hoped that this would provide more protection to employees in the event of the failure of the new organization and allow the parent company to rapidly scale or shrink. These staff were co-located in what managers referred to as 'the CreativeHub HQ', comprised of a half-floor in Fincorp's headquarters, based alongside the marketing department.

During the span of fieldwork, from December 2016 to May 2019, Creative Hub grew to become an organization with 108 employees. This period was also defined by the emergence of a range of persistent paradoxical tensions, underpinned by a structural dynamic that placed simultaneous, opposing demands on managers. Tensions emerged between the opposing demands for efficiency and flexibility, exploitation and exploration, revenue growth and professional recognition. We argue that these fulfilled the criteria of tensions normally studied by paradox theorists, representing persistent contradictions (Smith and Lewis, 2011), inherently built into the process of organizing (Jarzabkowski et al., 2013). These tensions appeared at multiple levels of the organization, forcing managers throughout the organization to make sense of their paradoxical qualities.

\subsection{Data Sources}

To capture how temporality becomes salient and influences how paradoxical tensions are negotiated, we adopted a longitudinal, process approach (Langley et al., 2013). The data from 
these sources were qualitative and interpretive in nature, to prioritise understanding how meanings are shared, challenged and influence action "in situations in which alternative meanings and understandings are present and possible" (Gephart, 2004, 457). To understand how meanings are created and their dynamic interplay with behaviours (Van Maanen, 1979), we used a range of ethnographic techniques to collect data. These allowed us to gain detailed, contextualised, and highly nuanced insights into the nature of the paradoxical demands inherent in the joint venture and the role of temporality. To increase both the richness and soundness of the data, we triangulated collection across multiple sources (Jick, 1979). This included direct participant observation over a period of three years, semi-structured interviews with senior management and content analysis of internal documents. In keeping with the phenomenological nature of this study, collection across each data source focused on capturing the lived experiences and understandings of organizational members.

Ethnographic Observation: In line with a process approach, our data collection prioritised events as a central construct for analysis (Langley, 1999). We gained access to CreativeHub during a period of extended fieldwork with Fincorp in 2016. One of the authors conducted pro-bono strategy support in CreativeHub's head office across five periods (T1-T5) between August 2016 and March 2019. During this time, we were able to collect data on working practices, observe planning meetings, and take part in organizational social events. In total, this amounted to more than 320 hours of participant observation. Using a field diary, we were able to continually record observations of the of discourse, behaviours and incidents that formed the basis of our primary data collection. Reinforced by the notion that collective sensemaking takes place in events (Maitlis and Christianson, 2014), this data formed an important starting point for much of our analysis. In an effort to capture the underlying meaning of these symbols and actions, we continuously recorded our immediate reflections on the meaning managers were intending to convey and the assumptions that underpinned their actions and discourse (Lincoln and Guba, 1985). These were used to guide our understanding of the organization and were regularly reviewed in light of new information.

Interviews: Interviews took the form of semi-structured conversations with individuals throughout the joint venture - Creative $\mathrm{Hub}$ - and also with senior managers from both parent organizations: Fincorp and Commcorp. In total, 80 interviews were conducted with 38 individuals. Interviews used a 'flexible protocol' (Gioia et al., 2012: 26) to allow conversations to be guided by the experiences and understandings of managers. This was 
further supplemented with daily brief and informal conversations with managers and staff members throughout the organisation to help grasp immediate responses to events and decisions. Clarification during the interviews referenced findings from other interviews and observed behaviour, rather than theory (Langley, 1999, 693).

Internal Documents: Observational data was triangulated with content analysis of internal documents and external analyst commentaries. In total, 62 archival documents were reviewed: including internal strategy memos, presentations, and briefing documents. Collectively, these were used to corroborate the narrative portrayed through interviews (Webb and Weick, 1979) and provided insights into the "intended image" (Brown et al., 2006, 102) that the organization's senior management sought to develop.

\subsection{Data Analysis}

A central aim of this research is to develop an understanding of how managerial understandings of, and approaches to, paradox change over time. To achieve this, we apply a process-driven methodology to emphasise the linkages of themes and concepts across time (Langley, 1999; Langley and Tsoukas, 2017). This combined an inductive, analytical approach to concept generation (Gioia, Corley and Hamilton, 2012) with the use of narrative techniques and vignettes (Reay et al., 2019) to highlight events and the patterns that link them across time. By combining these two techniques, we aim to balance 'showing and telling' (Berends and Deken, 2019: 5) - jointly pursuing both construct robustness and examples that bring their interplay in practice to life, and demonstrate the changes in the interplay of these constructs over time (Pettigrew, 1990).

Following the first phase of fieldwork (T1), we created a list of recurrent themes that had emerged from the first round of interviews. These themes formed the basis of 'hunches' (Lincoln and Guba, 1985: 186) regarding what managers understood to be relevant and pressing issues in the formation of the joint venture. To develop an understanding of how these might influence practice and behaviour, we began to link observed events (discussions, moments in meetings, responses to news) to these themes. We also began to identify how managers clustered according to their level of agreement with the themes we had established. Although only preliminary data, this first phase of analysis raised several issues that provided a starting point for deeper enquiry and suggested 'directions along which to look' (Blumer, 1954: 7). In particular, it became clear that there were differences in understanding (found in 
both interviews and observations) about what the firm was supposed to be doing, and what a good outcome would look like. Furthermore, it gave us an early insight into the extent to which these differences clustered around managers' industry and organizational affiliation (that is, whether they joined CreativeHub from Fincorp or Commcorp).

Following the second phase of fieldwork (T2), we began to analytically structure our growing data set. In the first stage, we coded observed events, internal documents, and interviews into first-order concepts. To help guide our understanding of the distribution of perspectives, we linked these where possible to the relevant individuals involved. Following the third phase of fieldwork (T3), we revisited this coding and supplemented it with additional codes that had emerged during the latest round of research. It was at this stage that temporal structures started to become relevant, with managers' explicitly and implicitly discussing urgency and differing time horizons. We began to cluster these first-order concepts into second-order themes. This process involved iteratively moving between data and theory to frame (Reineke and Ansari, 2015). In some cases, these themes were linked to terminology in wider theoretical discourse. It was at this stage that notions such as 'Temporal Depth' and 'Temporal Horizons' were built in as themes. Other themes, such as 'reputational benefit' and 'collegiate approach' grew out of terms used by respondents.

These codes and second order themes were further developed after both the fourth and fifth phases of fieldwork (T4 and T5), with new codes being added and existing codes and themes being reviewed in light of new data. Codes were ranked in chronological order (according to their emergence in the data) to capture the introduction of new concepts. From these themes we developed higher-order aggregate dimensions that guided the structure of this paper (Gioia et al, 2012, 21).

While this analytical approach helped us develop a robust and mutually exclusive set of codes and themes to guide our analysis, it is of limited use in accounting for change over time. Changes in process (Nicolini, 2010), and interplay between themes and processes (Tsoukas, 2017; Reay et al., 2019), are difficult to capture through such a 'snapshot' approach. To build on this, we worked chronologically backwards and forwards through the data structure to identify common threads (ongoing issues amongst managers) throughout all five phases of fieldwork, and changes to the ways in which these were addressed. We have structured the presentation of our findings around events and vignettes tied to these threads (Langley, 1999). Such an approach aims to draw out the interplay between different demands and temporal 
structures during episodes (events, moments) of collective sensemaking (Maitlis and Christianson, 2014). By focusing on a narrative approach linking vignettes, we hope to maintain the 'temporal coherence' (Berends and Deken, 2019:2) of the case, drawing out both consistencies and changes over time.

\section{Findings}

\subsection{Divergent Demands and Paradoxical Tensions}

When fieldwork began, latent tensions within the newly formed CreativeHub had begun to materialise in dialogue and behaviours between managers, and in concerns raised in T1 interviews. While managers did not explicitly refer to these tensions as 'paradoxical', they did describe an experience consistent with the definition of paradox - detailing a process of coping with contradictory, persistent demands that were understood to be inherent in the joint venture. There were multiple issues that made these tensions salient, at each point the fissure was a manifestation of contradictory demands captured in two paradigms: agency orientation and bank orientation. These paradigms within CreativeHub incorporated divergent understandings of the purpose of the joint venture, the relationship with the parent companies, and the form that success took.

The agency orientation emphasised an understanding of CreativeHub as an independent service provider to Fincorp. This emphasised a service driven operating model in which the bank was to be treated as a client, while CreativeHub was to maintain a distinct identity. Under this view, CreativeHub's primary value came from it's ability to provide expertise and creative vision not found within Fincorp, but with greater responsiveness and efficiency than a traditional agency. Success, under this orientation, was measured by two standards used elsewhere in the creative communications and advertising industries: creative reputation and revenue growth. The first of these demanded exemplar creative work, measured by industry recognition through awards, commentary and reviews. The latter derived from an understanding of the organization as a stand-alone independent business and placed an emphasis on winning an ever larger share of Fincorp's advertising and communications budget.

The second, bank oriented, paradigm was grounded in an understanding of CreativeHub as an extension of Fincorp's marketing and communications capabilities, and an alternative to 
external resource. The organization's value came from it's relative integration with Fincorp, adding resources to the existing marketing team. The organization was to sit as seamlessly as possible next to the marketing function to allow it to be a highly accessible resource, and an alternative to using agencies altogether. Phenomenologically, the joint venture would feel like an 'invisible extension' (Account Director) of Fincorp. In a more quantifiable sense, it would be seen as a success under this paradigm if it generated significant cost savings and efficiency for Fincorp's marketing function.

The differences between these two paradigms were most apparent when managers addressed the issue of what success looked like for the organization, and what the relationship with Fincorp and Commcorp should be. Managers circled - in conversation, interviews, and practices - disagreements about the relationship the joint-venture had with the parent companies and what the markers of success were. We detail these in Table 1 and elaborate below.

\section{TABLE 1 ABOUT HERE}

Discussions regarding the relationship with the parent organizations largely took the form of disagreements about the manner in which CreativeHub was expected to interact with Fincorp. The agency-oriented paradigm fundamentally underpinned the idea that this was a client service relationship. This involved treating the marketing and communications divisions of Fincorp in much the way that an agency would traditionally manage their relationships with clients. There was an emphasis on providing value by functioning as a 'source of external expertise' (Planner) and acting as a service provider. The agency-oriented paradigm underpinned an understanding that in day-to-day practice, Fincorp was to be treated as a client. In the early phases of fieldwork (T1-T2), this distinction primarily emerged through discourse. This included referring to Fincorp in all communication - including informal conversations as 'the client', replicating and reinforcing the traditional agency-client model found in the advertising and communications sector. This language was maintained partly through habit from those who had worked in an agency model previously; but also took on a normative 
element, representing a deliberate and conscious effort to shape how this relationship should work. This was captured in an interview with the Planning Director, who noted:

'This is something that is going to take a while to catch on. We need to do the normal client-service work: set up the meeting room in advance, get them a coffee, actually host it...people who previously worked in the bank really struggle with "serving" former co-workers, but we need to remember that we need something from them....we're not quite on the same team anymore. We're on cooperating teams.'

In contrast, the bank-oriented paradigm understood CreativeHub to be, first and foremost, an extension of Fincorp's marketing capabilities. In line with this, a large cohort of CreativeHub managers would refer to individuals within Fincorp as 'colleagues', in both documents and informal discourse. This was almost entirely made up of those who had previously worked for Fincorp and were seconded to the new joint-venture. As with the language used by those subscribed to the agency paradigm, this language was often used in a conversational and descriptive way, reflecting underlying beliefs about what CreativeHub was in relation to Fincorp. Occasionally however its use would be more deliberate and normative, reflecting strong beliefs about what the relationship between the two organizations should be. This can be seen in an early interaction between a CreativeHub Copywriter and Account Manager, discussing a campaign proposal:

CW: I know it's a bit of a bold idea, but [Art Director] and I think this is a winner.

AM: [Fincorp contact] and I have been colleagues for years and I just know he's going to want something a bit less punchy.

CW: Would you like me to sell the idea to him? Clients never know what they need.

A second point of difference that emerged at the outset was the way in which manners interpreted and discussed success, and the form this would take for Creative Hub. Our analysis found that, as with understandings of the relationship with the bank, the bank-oriented and agency-oriented paradigms defined interpretations of success. The agency-oriented paradigm supported a notion that CreativeHub's success would be measured by the standards of the wider advertising and communications industry. This involved maximising financial growth and seeking opportunities for creative recognition. For those brought in from Commcorp or the wider communications sector, the model of success required repeated increases in revenue 
through winning ever larger shares of work from key clients. This was in part driven by the inherent volatility of the communications sector; as one Account Director put the matter: 'the term "retainer" is misleading, clients can and do move agencies very quickly'. From the outset, this interest in growing the revenue received from Fincorp was openly discussed by managers who had moved into the role from elsewhere in the communications industry. This was captured in an interview with the first of two Managing Directors in place during the fieldwork:

'There will be opportunities to take a bigger slice of the global Fincorp business. So part of our job is to keep an eye on that and treat this period as an extended pitch...It's a chance to prove that this is the future of advertising; not just for Fincorp but for our whole industry'.

Our analysis found that the agency-paradigm also underpinned a view of success tied to a reputation for high-quality creative work. This was drawn from the importance of creative recognition within the advertising and communications professions, which provided a complimentary, but distinct standard from which to view success. Creative recognition mattered in part because it helped grow an agency by attracting clients, but also because of the importance of reputation in the careers of individuals in creative industries. As one Art Director put it: 'even in a job you're sort of self-employed. Your career hangs less on where you've worked and more on your portfolio of work. Specifically, the work that has been used and recognised. It's a long game'. This placed an emphasis on providing work that was novel, challenging and produced at a large enough scale to affect audience behaviour.

This prioritization of revenue growth and creative recognition differed substantially from the efficiency-driven model held by those who subscribed to the bank-oriented paradigm. Under this view, the primary purpose of CreativeHub was to increase the financial and operational performance of Fincorp's marketing and communications teams. By understanding CreativeHub as an 'extension of the bank' (Account Manager), its success was defined on the same terms as groups within the bank. This meant focusing on cost efficiency and operational flexibility, as one Account Manager noted: 'they can't really be ignored. We have to demonstrate value in pretty much everything we do'. This was reinforced by a 'culture of resourcefulness' (Account Manager) within Fincorp, which had emerged over the course of eight years since the financial crisis. Early interactions within CreativeHub referenced these 
conditions. This was noted in a meeting about an internal communications campaign, between an Account Manager and a Creative Director:

AM: 'We have to prove that were doing more with less. Anything that looks expensive will backfire and end with us being reminded that they were bailed out be the taxpayer'

CD: 'It's not about doing something expensive; it's about doing something properly... It's far more wasteful to spend money on half-doing this and having no impact'

The tension between these understandings of success worked at multiple levels. The agencyoriented pursuit of greater revenue for the joint venture, and the bank-oriented focus on efficiency were underpinned by organizational pressures and expectations from the respective parent companies. However, these pressures also operated at an individual level, with industry norms setting standards that managers used as a personal benchmark of achievement.

Our analysis showed that these differences were distributed largely according to the professional background of the managers, with those who had joined the organisation from Commcorp or other advertising agencies aligning to the agency paradigm, while those who had joined from Fincorp aligning to the bank paradigm. Due to the nature of the roles and the forms of experience required, these individuals were distributed in a clearly demarked way. Managers who had previously worked for Fincorp were seconded into account handling and client service roles - including positions as Account Managers and Account Directors. Those who joined from Commcorp or the wider advertising industry were drawn into specialist roles - including the creative team (responsible for the development of campaigns and communications), the planning team (responsible for research and strategy), and the production team (responsible for the creation of content). The result of this was that, while alignment to the paradigms was not dependent on a manager's position within the company, teams in the organisation aligned to different paradigms.

\subsection{From Latent to Salient Tensions}

A shift occurred in T2, with the latent differences noted in T1 developing into salient, explicit tensions. Our analysis found that this occurred in situations in which financial or capacity limitations forced managers into pair-wise choices, with the bank and agency-paradigms falling at either end of a spectrum. Discussions in these contexts brought latent tensions about 
the relationship with the bank and the measures of success into the open, reinforcing the dichotomy and forcing managers to explicitly confront the challenge.

This took several forms, but consistently involved either financial or capacity constraints limiting the options available to managers and forcing them to pursue a path that was either consistent with the bank or agency-oriented paradigm. This could be seen in a discussion during the third phase of fieldwork regarding the hiring of a high-profile Copywriter. Higher than usual salary expectations surfaced a tension between the agency-oriented pursuit of creative recognition, and the bank-oriented perspective that success was to be addressed through cost efficiency. This could be seen in discussions between the Creative Director and an Account Manager:

AM: 'I mean, we could hire two new people for that. At least that would solve our capacity'

CD: [interjecting] '-but this is what top people cost, and one experienced person who know what they are doing is more valuable for us.'

These tensions were especially pertinent in conversations regarding pitching for 'off plan' business. Part of the agreement behind the formation of the joint venture was that would conduct an agreed quantity of work for Fincorp's marketing department under an annual fee. Work outside of this remit - including work for other Fincorp departments or large ad-hoc projects - would be competitively tendered and pitched for in the usual way. This meant that CreativeHub would occasionally pitch for additional work alongside external agencies. Doing so surfaced tensions between bank and agency-oriented understandings of the relationship with Fincorp and the nature of success for CreativeHub. As the Traffic Manager noted: 'I think people who don't have that agency background struggle to see that winning new business is important for survival and the success of the whole operation, not just a vanity project'.

Discussions such as these began to highlight the intrinsic links between the two tensions. Prioritising cost efficiency was invariably tied to understanding that the joint venture was - in working practice if not organizational form - an extension of Fincorp. Focusing on growth and creative recognition highlighted it's separateness and affiliation to the wider advertising industry model. The links between the poles of the paradox and beliefs about these topics are captured in Table 2. While the two paradigms were present from the formation of the joint venture, their contradictory qualities were drawn out around through the process of organising 
and became salient tensions when addressing issues where their respective approaches were incompatible.

\section{TABLE 2 ABOUT HERE}

\subsection{Early Trade-Offs and Paradoxical Thinking}

Managers did not refer to these tensions as paradoxical, yet in interviews across the joint venture they would describe their dynamics in a manner consistent with the definition of paradox. This included a recognition of the persistence of these tensions and the notion that they inherently stemmed from the nature of the organization, as a conversation with the Director of Strategy captured: 'We need to provide some resistance, but if we focus too much on our own way of doing things then none of this will exist next year'. In interviews during the first two phases of fieldwork, there was a sense that this would be dealt with through adhoc trade-offs. Across all levels of the organization, an early consensus emerged that this was simply part of the dynamic of the organization: 'I think these debates are just part and parcel of the kind of organization that we are. It's not too hostile'. (Account Manager).

Over the course of the second phase of fieldwork, however, satisfaction with this approach declined as these tensions began to undermine the ability of project teams to make decisions and progress work. In some cases, this resulted in inertia. Discussions regarding whether to physical integrate CreativeHub into the offices of the Fincorp marketing team came to an impasse. Perpetual disagreement resulted in the initiative being paused. As the Traffic Manager noted: 'we will have to return to that at some point, but it's not worth pushing the issue now'. In other cases, tensions persisted after decisions were made. For example, discussions regarding hiring an 'expensive' (Account Manager) high-profile Creative Director continued even after the opportunity to poach a particular candidate from another agency had passed. With no decision left to be made, this manifested itself in a sense of frustration from those who had supported the idea: 'I'm annoyed that they dragged their heels so much, that would have really changed things around here' (Creative Director). A very similar sentiment emerged following a decision not to pitch for an additional piece of Fincorp Business, with 
the Planning Director noting that 'I know it was a long shot and we were really stretched with existing work, but it we're not going to compete then this won't last long.'

\subsection{The Emerging Salience of Temporal Structures}

By the start of the third phase of fieldwork (T3), we found that managers had developed a tendency to move away from discussions about what the correct course of action was to disagreements about what the most pressing issue was. With this came a recognition that the opposing perspective was valid, but disagreement about which approach should take priority. This was articulated clearly in an interview with a Production Manager: 'we're learning from each other. I know that their approach isn't wrong, they do have a point. That said, we know that this won't work if we just live week by week, project by project.'. While there was no attempt to address the underlying paradox - with decisions continuing to be made in a sequential, ad-hoc manner - it did mark the introduction of a temporal perspective to addressing tensions.

In discussing which concerns were more urgent, and which to address first, managers drew on two separate temporal concepts. Firstly, differences emerged in the distance into the future that managers considered when discussing goals. When discussing the long-term vision for the joint venture, the bank-oriented perspective would predominantly focus on the extent to which the organization was perceived as a success by senior individuals within Fincorp. This placed a relatively short timeframe on the understanding of the future, grounded in the career cycles of individuals and framing the organization as a 'project' (Account Manager). In contrast, those with an agency-oriented perspective would focus on the longer-term industry shifts that CreativeHub could contribute to, which placed a longer-term and less clearly defined limit on considerations about the future. As the group's Planning Director noted: 'we believe this can be a new model of working and could be very attractive to the advertising industry...demonstrating that is important if we're going to attract top people'.

A second point of temporal difference concerned the frequency of points at which progress was measured. The bank-oriented perspective drew on a relatively structured approach to benchmarking based on Fincorp's review cycles. This included demonstrating improved financial performance in Fincorp's quarterly Financial Review, project by project performance reviews and a bi-annual Agency Review meeting. This created a highly structured series of short-term markers from which success was measured. In contrast, the Agency-oriented 
perspective relied on more infrequent points, such as the pursuit of industry awards, media recognition, winning new contracts and attracting high-profile talent. The tension between these was captured in a discussion during a meeting between an Account Manager, Planner, and Senior Planner about the allocation of resources that was being given towards submitting case reports to industry awards ceremonies.

AM: 'Can we prioritise the audience impact reports for [Fintech contact]? I think they're due ahead of the D\&AD [industry award] submissions.'

P: 'I think we're going to have to split out the workload on that. The award submissions are due next week but we have a really good shot this time and they only come up once a year.'

SP: 'Yes, I think we need to block off time for that. We can't do it properly if we're putting out fires with Fintech all the time.'

From our analysis, we argue that these different ways of structuring conversations about time and urgency map onto the concepts of Temporal Depth - the distance in time that managers consider - and Temporal Horizons - the moments and waypoints that segment this overall depth. Table 3 maps the manner that this temporal structure was applied to the three ongoing issues identified in Table 2, above.

\section{TABLE 3 ABOUT HERE}

This marked a shift in the way in which paradox was processed. In discussing which issues to prioritize - rather than which was the correct course of action - managers softened their tone and adopted a more conciliatory approach. It also introduced greater awareness amongst managers about the temporal assumptions they held. This was noted by an Art Director during an interview, referring to the practices of those in the organization who were more aligned with the bank: 'they are just so focused on the day-to-day needs of clients, and don't really give us the time or space to produce good work. But I do understand that we sort of exist because we can give Fincorp that attention'. Amongst all levels of the organization, individuals became more aware of their own temporal assumptions and more sensitive to those of others. 
While this nascent temporal approach did change the way in which managers discussed the paradoxical tensions, conflict persisted. This took two forms. In day to day interaction, debates continued regarding which steps were a priority. This was captured in a discussion between an Account Manager and Traffic Manager about the amount of time being dedicated to the development of a new campaign over the production of a newsletter:

AM: 'I know it's difficult to give this resource, but it's important to get it out this week'

TM: 'Yeah I understand that it's due soon but we also have a few big things coming up...I'll see if I can move someone on to it for a few hours'

Alongside this, disagreement continued about the long-term aims of the organization. The existential nature of this question meant that it would normally appear in conversation between managers who aligned to similar paradigms, but would not naturally be brought up during conflict. This could be seen in a joint interview with two Copywriters who had moved to CreativeHub from a traditional advertising agency:

C1: 'I think we want to be known for two things: great creative work, and growing an ad agency in an entirely new way.'

C2: 'Yeah, but that's hard when you're in an environment that is geared towards benchmarking every step of the process. It's sort of anathema to great creative work.'

Our findings at this stage highlighted the role that the commitment to a longer, continuous temporal depth allowed those aligned to the agency paradigm to accommodate irregular and infrequent temporal horizons. In contrast, the short, sequential temporal depth of the bank paradigm accommodated regular and highly predictable horizons. These differences in temporal structure resulted in ongoing tensions. For those aligned with the agency depth, frequent and regular horizons were seen as a 'bureaucratic' (Creative Director) distraction from the higher aims of the organisation. For those situated within the bank paradigm, the irregular horizons of the agency paradigm appeared 'distant' (Account Manager) and irrelevant. This interaction between the different temporal structures of each paradigm is captured in Figure 1. 


\section{FIGURE 1 ABOUT HERE}

\subsection{Addressing Paradox Through Renegotiated Temporal Structures}

These tensions persisted over the course of T3, and became increasingly salient in interviews. Mangers described the ongoing dynamics as 'frustrating' (Copywriter), 'challenging' (Account Executive) and 'tiring' (Creative Director). An interview with the Planning Director captured the ongoing strain particularly succinctly:

'Don't get me wrong, there is a clear reason for us to exist: we clearly provide value to Fincorp and Commcorp. The challenge comes from the fact that providing that benefit to both of them takes a lot of ongoing work. It looks like a black box from the outside, but on the inside it looks like a cartoon fight - a cloud with fists and legs sticking out.'

The beginning of T4, in October of 2018, saw a change in the senior leadership team. The most notable change was a new Manging Director tasked with 'bedding us in and providing some stable growth' (Planning Director). This created a window of opportunity to assess the organization's strategic priorities and provide a new sense of direction before the Annual Review, which was due in late January 2019. The purpose of this review was to evaluate the performance of the organization to date and it's future approach. There was a sense amongst the management team that the timing of the review made it more significant than it had been in the previous year: 'We're at the stage now where we can identify what was a teething problem, and what is more systemic. I think that makes it easier to identify what we need to change. There is a bit of a mandate to reset the things that aren't working now that [the new Manging Director] has come in.' (Account Director). One of the central aims of the review process was to set out 'a really well articulated proposition for what we are doing' (Planning Manager).

There was a recognition that this process would involve a strong temporal element. As was noted in an interview with the new Managing Director: 'we need to develop a vision of the 
future, a clear picture of where we are aiming. Something that people can get behind and will capture what we're doing here'.

Negotiating Temporal Depth. This temporal element was brought out particularly strongly in discussions about the organization's strategic proposition. CreativeHub's Traffic Manager responsible for managing the allocation of work within the Creative and Strategy teams noted that 'you have to take into account what drives people. No self-respecting Creative Director wants to focus on the day to day of running a marketing department, but it's equally frustrating for anyone seconded from Fincorp to focus far ahead when there are so many fires to put out'.

Discussions regarding temporal depth became central to the development of the revised strategic proposition. A consensus began to emerge that those who had joined the organization from the bank would need to relax their focus on short-term results and find value in the more distant future. This was highlighted in an interview with a Senior Planner, who discussed the way in which meetings were being run: 'they just don't understand that we are trying to build something new here. There is an entrepreneurial approach where we don't limit ourselves or our ambition, but they just see this as a very functional exercise.'

Simultaneously, some managers raised concerns about the way in which those with an Agency background talked about their vision for the organization. This was captured in an interview with an Account Manager when discussing a description of CreativeHub - given by the former Managing Director - as a 'brand-defining creative agency': 'I mean, it's a bit nebulous, isn't it? It's not just the language, it's that it's so ill-defined. How and when do you measure that?'

These forces contributed to a sense that a degree of compromise was required on both sides. A revised temporal depth was developed that was facilitated though an adjustment to the temporal depth held by each side. On the one hand, managers aligned to the agency paradigm took steps to shorten and define the span into the future they considered. Simultaneously, those aligned with the bank paradigm softened and extended their considerations of the future, to take in a broader span of time. These revisions to previously held understandings of temporal depth were noted in discussions and interviews throughout T4.

Shortening and defining Agency Depth. Over the course of T4, managers began to refer to the future of the organization in narrower ways. This was first noted in a 'All Hands' meeting 
shortly after the arrival of the new Managing Director, in which they referred to the organization as 'an exciting project - this is something that hasn't really been done on this scale before'. This reference to CreativeHub as a 'project' was echoed in subsequent conversations with senior management, including references to CreativeHub as 'an experiment' (Senior Planner) and a 'new sort of venture' (Account Director). These terms marked a significantly shortened temporal depth, limiting visions of the future to the success of the organization's medium-term relationship with Fincorp, rather than the longer depth of agency lifespans and career reputations in the advertising industry. This shortened temporal depth was reinforced by the use of more defined temporal boundaries by senior management, providing managers with a defined reference point when considering the future. This was captured in a meeting between an Account Manager, the Planning Director and the Managing Director about the framing of the forward vision section of the annual review.

AM: I think when you look at other agencies, take [agency x] or even [agency y], there's this clearly defined vision: [agency $x$ vision]. But what we have is so vague and open ended.

MD: Agreed. I think it's important to remember that the main aim when this started was to build some energy. We're moving into a new phase now where we need to be a bit more focused.

AM: I think that would help with our relationship with Fincorp too. The dividers between us are very porous, so whatever we say internally will be heard by people outside too.

PD: Pragmatic but without throttling the ambition too much, I think that's the aim of this exercise.

MD: [PD] - we talked briefly about focusing on targets, but using these sort of soft targets

PD: Yes, I think rallying around this idea of this being a project and seeing how far we can get in the next couple of years. We don't need to verbalise actual targets, but maybe focus the mind a bit more. 
Softening Bank Depth. The reference to the 'experimental' nature of the joint-venture had a dual-sided function. On the one hand, it shortened the expansive temporal depth of those working with the Agency paradigm. On the other hand, it appeared to soften the hard boundaries of temporal depth used by those working with the Bank paradigm. By adjusting the depth considered from bi-annual cycles with hard limits to a broader 'vision for the project' (Account Manager), those who had previously drawn on the Bank paradigm began to use a more expansive approach. An interview with the Traffic Manager captured this: 'Part of being in a service industry is that sometimes you know what is better for your client than they do. There is a reason Fincorp didn't simply hire people to work within their marketing department, and that is that we understand how to do this in ways that they don't - they will get better results if they give us that little bit of extra slack on the lead'. Similarly, an interview with an account manager noted that: 'we are still effectively competing with external agencies. We can't simply be a print shop, we need to add more value but that takes time to develop'.

This revised temporal depth - negotiated from an expansion of the depth associated with the bank paradigm, and a tighter definition of the depth associated with the Agency paradigm was solidified throughout the 'forward vision' section of the internal review document. This referred to CreativeHub as: 'A collaborative project... introducing a new way of working'. It made frequent references to a two-year timeframe: 'CreativeHub has had a strong start...We're well set up to grow over the next two years; producing our best work, delivering for Fincorp, and growing an agency to be proud of.', 'The next two years are our opportunity to deliver something radically different'.

Accepting Mutual Interdependency of Temporal Horizons. Our analysis showed that in T5 - following the negotiation of a revised, shared temporal depth - managers began to understand the temporal horizons associated with each paradigm as interdependent in fulfilling the strategic vision. In observed discussions and follow-up interviews during T5, managers drew on the revised temporal depth of the strategic vision when discussing their own horizons and those of the opposing paradigm. Managers on either side of the original paradox drew on the revised vision to come to an understanding of the necessity of acting in line with both sets of temporal horizons. This was captured in a meeting between the Traffic Manager, and Account Manager and a Senior Planner regarding allocation of time to projects:

AM: I think [individual within Fincorp] would like the report on media ROI for the quarterly. 
TM: Yep - [Senior Planner] needs to be in Manchester and Birmingham for the focus groups this week, plus everyone needs time to get the ideas on the (B2B Proposition) launch prepared. Maybe we coul-

AM: Is there any way we can get that finished any sooner?

SP: We can get them something, but we (the planning team) need some more data and the creatives need some more refining time to create something really compelling.

TM: I think [Creative Director] is putting a lot into this one. There is rumour of extra business coming up with [International Business Banking division] so we need to impress on the B2B side. [Managing Director] is treating it as a bit of a proof-of concept of what we can do.

SP: I think winning [this contract] is pretty crucial to steadying things next year.

AM: Okay, I'll push back a little bit on [individual within Fincorp] and see if we can use other data to make the ROI point. But we do need to have a look at locking in time every few months to deliver this too.

Tensions between the frequent, short horizons of the bank paradigm - captured in the alignment to Fincorp's quarterly reporting - and the longer, irregular horizons of the Agency paradigm - found in the pursuit of reputable work and new business - are navigated by using the revised temporal depth as a point of reference. By referring to the revised depth, the Senior Planner and Traffic Manager are able to elicit a degree of understanding from the account manager about the importance of pursuing achievements measured at horizons typically associated with the Agency paradigm, rather than with the Bank paradigm. This use of a longer temporal depth provides room for a wider range of horizons, all contributing to fulfilling the notion of 'success' captured in the medium-term strategic vision.

The revised temporal depth also highlighted the value of shorter, frequent temporal horizons to those who had previously aligned to the Agency paradigm. By moving to a medium-term, clearly defined temporal depth of two years, the value of frequent horizons at regularly spaced intervals became apparent. This was captured in an interview with the group's Creative Director, who noted that: 'I think we started this with a bit of hubris about what we could achieve, but we don't really have time to deliver traditional long-form campaigns. But there 
is still interesting work to be done, we just need to prove that we are useful to them (Fincorp) and build from there'. Similarly, an interview with a Senior Copywriter highlighted the shift in mentality that had been brought in by more defined temporal depth:

I think part of the challenge for us is finding joy in quick-turn around, smaller, projects... but maybe this project is just a whole new way of being creative - it rewards wit and clarity over big, integrated campaigns...I think that work can be exciting in it's own way, but it's not what we're used to'.

\subsection{Sustained Paradox, Mitigated Tensions}

Combined, the act of negotiating a revised temporal depth and accepting the interdependency of different temporal horizons influenced how individuals processed the paradoxical forces between the agency and bank paradigms. By negotiating a shared understanding of temporal depth, managers were able to orient around a vision of the future that necessitated working to frequent, short term horizons (such as bank quarterly targets) and moments reached at less regular and more distant intervals (including achieving industry recognition and winning new business). Managers from the Bank paradigm were able to integrate a greater variety of temporal horizons under the revised temporal depth, which was broader than their own. In parallel, by moving to a clearly defined temporal depth, managers from the Agency paradigm were able to treat milestones at regular, frequent intervals as pressing and necessary. We have illustrated this in figure two, which captures the revised temporal depth as a locus for processing both sets of temporal horizons.

FIGURE 2 ABOUT HERE

Our findings suggest that this temporal structure helped to reduce conflict between the two paradigms, while maintaining their distinct demands on the organization. An important distinction in our findings, therefore, is that the temporal horizons associated with each paradigm were maintained. The presence of a common temporal depth that is sufficiently broad yet well-defined allowed for multiple temporalities to co-exist. 
This revised temporal depth played an important role in allowing CreativeHub to pursue both the frequent and regular targets of the bank paradigm and the less frequent goals of the agency paradigm. Circumstances that previously drew out tensions between the two paradigms were now processed with reference to a shared temporal depth, allowing and/ or solutions to be facilitated more easily. This could be seen in an interaction between an Account Manager and Account Director regarding the allocation of time to new campaigns and pitches for new business:

AD: I want to try to get [Senior Planner] on the B2B campaign too. I'll speak to [Traffic Manager] this afternoon about that.

AM: I think [Senior Planner] is pretty snowed under with the pitch for [digital proposition] this week. Maybe we could-

AD: [interjecting] -ah that's a good point. I think that's pretty important for us. I'll see if we can maybe bring in [Freelancer] for the next week so we can get both moving.

This pursuit of both/ and settlements appeared across the joint venture. In discussions regarding recruiting high-profile candidates for the creative team, discussions incorporated an admission that money did need to be spent, but that it would now have to represent value for money over the next two years. This allowed requirements of each side to be met through a compromise agreement in which the criteria for a new hire were changed. This was noted in an interview with one of the Creative Directors:

'We've sort of shifted what we're looking for. Key thing is getting people in who can have a pretty immediate impact and take on some management roles. The idea of getting a famous big name in as a sort-of 'Creative Tsar' didn't go down well, but I'm just glad that we're going to spend some money.'

Discussions regarding physically integrating CreativeHub within the Fincorp marketing department was similarly dealt with through a both/and approach. A settlement emerged in which Managers decided to 'keep our own sense of space' (Copywriter) while simultaneously creating a sense of perceived accessibility: 'we're trying to make it feel like we're very involved consultants. We have a hot-desking space in their office, and they have one in ours. We're also going to try out short-term secondments each way' (Traffic Manager). 
We have outlined an illustrative set of these cases in Table 4. These discussions previously involved ongoing tensions between competing demands (Table 2) and incompatible temporal structures (Table 3). The introduction of a shared mid-length temporal depth gave managers a framework with which to accommodate the demands of the other side. This resulted in a shift towards an both/ and settlement.

TABLE 4 ABOUT HERE

Interviews further reinforced the notion that managers drew on a shared temporal depth to accommodate previously competing temporal horizons. A Planning Director noted that: 'I may not spend my whole career here, but this is an interesting project. Making it work will need us to do what we need to do to keep Fincorp happy'. Similarly, an Account Manager noted in a follow-up interview that 'we've become better at losing that day-by-day mindset and giving them time to develop. It puts more pressure on us but it's part of the job'. By accommodating both sets of horizons, managers were able to make decisions that satisfied both parent companies, an important condition for its survival.

While managers demonstrated an ability to accommodate the horizons of each side, interviews highlighted that this did not amount to a belief that the practices and objectives of each side were necessary or complementary. Managers understood that both frequent, short-term demands and infrequent, longer-term demands had to be met within the scope of the two-year vision; but did not fully transition to understanding the paradigms of the opposing side as necessary or complimentary to their own. A Planner noted in an interview that 'They (Fincorp) are not colleagues of ours, and I don't think we should think of them like that. But if our survival involves creating the illusion of being on the same team then that becomes part of the job'. Similarly, an account executive claimed, when discussing the amount of time being givent to creative teams, that: 'their projects aren't business critical, but we have to create the space to let them do that. Otherwise [those individuals in the Creative team] will all choose to 
leave in a few months'. While managers did not come to understand each other's objectives as necessary, they were able to functionally accommodate each other's temporal horizons, and the goals associated with these, within a shared temporal depth.

\section{Temporality in Paradox - Toward an Integrated Model}

Our analysis found that managers engaged with a paradox that was initially construed as atemporal through an emerging temporal reflexivity (Orlikowski and Yates, 2002; Tsoukas, 2009). Through this, the temporal dimensions of the paradoxical tensions were increasingly understood to be the relevant and malleable. This reflexivity enabled a negotiation of a shared, defined temporal depth which accommodated the temporal horizons of each side. We argue that collectively, these processes enabled managers within the joint venture to approach the paradox from a new perspective; minimising tensions while maintaining distinct elements of each paradigm. We argue that the application of temporal reflexivity to paradoxical tensions provides new pathways for understanding how paradox can be processed.

The process of temporal reflexivity outlined in this paper emerged in interrelated phases. In the first phase, temporal structures became increasingly salient in discussions regarding paradox; resulting in an interpretive shift, orienting discussions on the differing temporal assumptions of each side. Our case demonstrates how temporality becomes increasingly salient through organic discussions of sequencing and long term aims: as managers discussed which tasks to prioritise and what their more distant aims were, they surfaced the different temporal structures within each paradigm. As a result, surface-level tensions were discussed in new terms with temporality at their centre. While prior studies have explored the role of temporal reflexivity in helping managers address differences in their approach (Reinecke and Ansari, 2015), our model goes further by demonstrating how this emerges organically out of a paradox that is initially construed by managers with little reference to temporality.

This interpretive shift enabled an iterative reinterpretation of each paradigm's temporal depth, allowing for the creation of a new shared understanding. We argue that this shared temporal depth had two structural qualities that allowed for the accommodation of the temporal horizons of each side. First; while the mid-length, two year span of the revised temporal depth was novel to both sides, it was able to accommodate and maintain a fit with their respective horizons. For those aligned with the agency paradigm, the new depth still allowed room for the relatively infrequent horizons associated with creative work and agency milestones to 
materialise. For those aligned to the bank paradigm, the span of two years was sufficiently close that frequent quarterly milestones could contribute to success at the end of the revised depth. Secondly, the explicit articulation of a defined depth with firm boundaries provided an identifiable point in time for which achievements at each horizon should build to. Our findings suggest that refining the depth to extend to this specific point in time (two years, prior to the annual Fincorp Leadership Meeting) decreased the vagueness and abstraction with which managers referred to the future. This, in turn, facilitated a greater appreciation amongst managers' of the precise ways in which both sets of horizons would materially build towards success at that point in time.

Crucially, this process of emerging temporal reflexivity, and the structural qualities of the revised temporal depth (mid-length, with a clearly defined boundary), enabled horizons from both sides to be accommodated while mitigating conflict. Managers recognised that addressing both sets of horizons would allow the joint venture to fulfil it's role as both a creative agency and a seamless extension of the bank, a crucial requirement for the survival of the organization.

\section{Discussion}

This paper set out to explore how managers can utilise temporal structures in addressing paradoxical demands. We argue that our findings raise important implications for both the paradox literature and the study of temporality. We conclude by exploring future paths for research.

\subsection{Implications for the Paradox Literature}

Our work adds to a growing body of research that seeks to capture the phenomenological and ontological complexity of paradox (Schad and Bansal, 2019; Palermo et al., 2019) by 'switching theoretical lenses' (Nicolini, 2009: 18) to bring new dynamics to the fore. In doing so, we go beyond the 'salient perceived tensions' (Schad and Bansal, 2019: 3) of the case and explore the temporal structures and understandings that reinforce these tensions. Our case has shown that focusing on this temporal interplay provides important contributions to our understanding of paradox.

Quasi-transcendence and the accommodation of competing demands. By working through the processes of temporal reflexivity and developing a revised temporal depth, managers were able to accommodate distinct temporal horizons aligned to two contradictory paradigms. 
Rather than existing in competition (Ancona et al., 2001), managers treated these temporal horizons as constituent of the revised temporal depth. Managers were able to work towards temporal horizons that originated from either paradigm, pursuing behaviours consistent with both sides of the original paradox.

While this outcome was consistent with paradox theory's pursuit of 'both/ and' solutions (Poole and Van de Ven, 1989; Lewis, 2000), it is achieved without the requirement that managers 'view both paradigms of the paradox as necessary and complementary' (Bednarek et al., 2016: 78). Managers used the revised temporal depth to accommodate the temporal horizons of each side, without fully embracing the opposing paradigm as necessary or complementary. We argue that this 'quasi-transcendence' - in which individuals accommodate the opposing demands associated with each paradigm without understanding each as necessary - allows mangers to fulfil demands from both paradigms while mitigating tensions.

As in the pursuit of transcendence, managers were able to maintain and address the distinct paradigms of each side to fulfil their dual role (Farjourn, 2015; Jarzabkowski et al., 2015; Smith et al, 2017). By deconstructing opposing demands into their temporal structures, managers were able to develop a more nuanced approach, negotiating shared elements while keeping others distinct. Doing so allowed for a sustained interplay between the opposing demands of each paradigm; an outcome that was not possible when managers focused on the binary surface-level tensions. In discussions regarding hiring, for example, a shared temporal depth of two-years allowed managers to accommodate both the regular, frequent budgetary horizons of the bank paradigm and the less frequent recognition-focused horizons associated with the agency paradigm. Through this, managers were able to develop a provisional settlement, while maintaining their respective interests and horizons.

We argue that, in cases where managers are unable to alter their understanding of opposing demands, an approach focused on the interplay of temporal structures can allow managers to accommodate and pursue competing goals. This is particularly relevant in collaborative arrangements such as joint ventures, where actors are likely to draw on pre-established norms and expectations from their prior affiliation (Greenwood et al., 2011; Kraatz and Block, 2008).

Paradox and temporal reflexivity: the process of a temporal 'interpretive shift'. While previous studies have explored the role of temporal sensemaking (Reinecke and Ansari, 2015; 
Tsoukas, 2009) and temporal interplay (Schultz and Hernes, 2019; Slawinski and Bansal, 2015) in shaping intra-organisational tensions, the process by which temporal structures become both salient and central to navigating tensions has not been explored. Our work provides a process-led (Langley et al., 2017) model of how temporal structures become the salient lens for addressing paradoxical tensions, and the subsequent temporal mechanisms that managers use to address competing demands.

Our work shows that through a growing 'temporal reflexivity' (Giddens, 1990; Orlikowski and Yates, 2002) managers became awareness of the temporal structures of each side, and the 'potential for reinforcing and altering' them (Orlikowski and Yates, 2002: 698). This reflexivity emerged organically as managers moved their focus to the problem of which tasks to prioritise, following less fruitful discussions about which to pursue. Through these discussions, managers surfaced the underlying structures of temporal depth and temporal horizons. Crucially, this process resulted in mangers becoming aware of the "potential for reinforcing and altering' these temporal structures (Orlikowski and Yates, 2002: 698). While managers didn't use the vocabulary of temporal depth or temporal horizons, they were able to identify the differences in the overall span of time considered, and the intervals that broke these up. This made it possible for discussions to focus on the soundness and appropriateness of the assumptions they held about time. In practice, this manifested itself as discussions about the how far into the future they needed to consider, and whether immediate, regular demands were more important than less regular expectations.

We show how this temporal reflexivity enabled a subsequent renegotiation of temporal depth, resulting in a structure that accommodated both sets of temporal horizons. By renegotiating a strategic vision with a shared temporal depth, managers were able to appreciate and accommodate the horizons of each side (Slawinski and Bansal, 2012; Bluedorn and Martin, 2006). Collectively, these mechanisms represent an 'interpretive shift' (Staudenmayer et al., 2002), which allows managers to explore competing paradigms through their complex temporal structures.

The multi-faceted nature of temporal structures allows for more complex interplay than between the binary demands that exist in surface level tensions between competing strategic goals. Early in the case, discussions regarding whether or not to proceed with a course of action drew heavily on industry-level understandings of what success looked like. These often resulted in binary 'either/or' debates, with managers supporting the course of action (or 
inaction) that fitted best with their understanding of success. By breaking these understandings into their respective temporal depth and horizons, it became possible to negotiate a shared aspect (in this case, a shared depth at a compromise length of two years), which accommodated both sets of horizons. Through this shared structure, it was possible for managers to resolve tensions and come to provisional settlements, while maintaining the distinct expectations of each side. This work extends research into the interplay of temporal structures in resolving tensions (Schultz and Hernes, 2019) by developing an account of the mechanisms that enable such interplay.

\subsection{Implications for the study of Temporality}

The interplay of temporal structures - mitigating and reinforcing paradoxical tensions. Our analysis found that a sustained interplay was only possible once managers had altered the underlying temporal structure. The creation of a revised, compromise temporal depth with a defined end was able to accommodate the temporal horizons of both groups.

We argue that this has two implications for our understanding of temporal interplay. First, we propose that it is possible for sustained temporal interplay to occur between opposing strategic positions, made up of 'couplets' of temporal horizons and their associated temporal depth. This inter-group interplay (where each group holds it's own understanding of temporal depth and it's own temporal horizons) suggests that temporal interplay may be more multifaceted than has previously been argued. We argue that this case extends the work of Schultz and Hernes (2019), who found that reconceptualising organizational identity with a more explicitly defined temporal depth enabled a sustained interplay with the temporal horizons of the firm's strategy along with an increased divergence of strategic horizons (2019: 129). We confirm how temporal interplay can accommodate multiple, divergent horizons, but show how such temporal interplay emerges and take presence among mangers from opposing paradigms. Also, we extend these findings by outlining the interplay between two opposing couplets of temporal depth and horizons. We show how a shared depth with the structural qualities of a compromise span, and a defined boundary can accommodate multiple, divergent horizons. This model emphasises the central role of a shared temporal depth in facilitating sustained interplay, bridging what were previously competing couplets. In cases where the temporal structures of competing strategic understandings vary significantly, developing a mid-length shared temporal depth can allow managers to accommodate the horizons of each side, mitigating tensions and allowing outcomes at both sets of horizons to be met. 
Secondly, we argue that while revised, shared temporal depth has the capacity to mitigate paradoxical tensions, maintaining distinct temporal depths may reinforce the existing paradox. In our case, the emergence of a temporal shift alone did not mitigate tensions. Rather, the presence of distinct temporal depths reinforced the exclusion of the opposing paradigm's temporal horizons. In doing so, it served to reinforce ongoing tensions (Figure 1). It was not until the temporal depth was renegotiated that a sustained interplay was possible. Our study contributes to a growing body of literature that places temporality at the heart of studies of paradox (Slawinski and Bansal, 2015; Reinecke and Ansari, 2015). We argue that our findings support the notion of temporal structures and their interplay as a substantial and central component of organizational paradoxes; capable of both perpetuating and mitigating their tensions.

\section{Limitations and Future Research}

We acknowledge that our use of a single-site participant observation led study brings inherent limitations. Our choice of methodology for this study was intended to increase the richness of data and provide insights into the unfolding of processes over time (Nicolini, 2010). The lessons from this case are intended to be a theory-building (Lee et al., 1999) exploration of the role temporal structures and temporal reflexivity have in the processing of paradoxical demands. In doing so, however, we recognise that we have limited the generalizability of our findings. We recognise that parts of our analysis could be furthered by research that adopts a positivist, hypothesis-testing epistemology. In particular, this could be used to solidify our understanding of the link between temporal depth and temporal horizon diversity.

Further research may be needed to establish the long-term sustainability of the temporally reflexive process outlined in our case. As detailed in our analysis above, the mutual appreciation of temporal horizons was an ongoing process of 'reinforcing' (Orlikowski and Yates, 2002) the fit between both sets of temporal horizons and the revised temporal depth, underpinned by the recognition that both were 'inextricably linked and mutually influential' (Chen and Miller, 2011, 23). Whether this ongoing process was sufficiently stable to be maintained over the long term could not be captured within the scope of this study. Further research could explore the socio-cognitive forces and processes that contribute to the maintenance of a mutual appreciation of temporal horizons. 
Finally, we acknowledge that our model in this case is not exhaustive. As was discussed in the front half of this paper, research has shown that a number of additional forces can contribute to the manner in which managers process paradox. This can include organizational identity (Jay, 2013; Smith and Lewis, 2011), environmental demands (Cameron and Quinn, 1988), and cognitive frames (Hahn et al., 2014; Putnem et al., 2016; Schad et al., 2016). These forces were not observed during our fieldwork, but the extensive body of literature on these topics suggests that they could concurrently influence how the organization processes paradox. Further research could explore the interplay between the temporal mechanisms identified in this study and topics such as identity and framing on managers' responses to the paradoxes inherent in hybrid organizing.

\section{Tables and Figures}

Table 1: Latent Tensions

\begin{tabular}{|c|l|l|}
\hline & \multicolumn{1}{|c|}{ Agency Paradigm } & \multicolumn{1}{c|}{ Bank Paradigm } \\
\hline Nature of Success & $\begin{array}{l}\text { - Industry reputational gains through } \\
\text { creative recognition } \\
\text { Revenue growth }\end{array}$ & $\begin{array}{l}\text { - Reputational gains within Fincorp - } \\
\text { to be seen as a reliable and effective } \\
\text { extension } \\
\text { Cost efficiency }\end{array}$ \\
\hline Relationship with Parent Organizations & $\begin{array}{l}\text { - Deliberately external to Fincorp } \\
\text { - Aim to replicate a client-service } \\
\text { relationship }\end{array}$ & $\begin{array}{l}\text { - Heavily integrated secondary resource } \\
\text { for Fincorp } \\
\text { Belief that individuals in Fincorp } \\
\text { Treatment of individuals within } \\
\text { Fincorp as 'clients' } \\
\text { Emphasis on speed, responsiveness } \\
\text { Emphasise expertise and } \\
\text { independence }\end{array}$ \\
\hline
\end{tabular}

Table 2: Ongoing Intra-Paradigm Tensions 


\begin{tabular}{|c|c|}
\hline Ongoing Topic & Response \\
\hline \multirow{2}{*}{$\begin{array}{l}\text { Discussions regarding } \\
\text { recruiting high profile } \\
\text { candidates for the } \\
\text { creative team. }\end{array}$} & $\begin{array}{l}\text { Agency: Broadly positive. Emphasis on the reputational gains that } \\
\text { would raise the profile of Creative Hub. Prospect of further } \\
\text { recognition through industry awards. }\end{array}$ \\
\hline & $\begin{array}{l}\text { Bank: Hesitant. Discussions cited the expense and the issue of } \\
\text { efficiency in the annual reports. Emphasis on getting better value for } \\
\text { money. }\end{array}$ \\
\hline \multirow[t]{2}{*}{$\begin{array}{l}\text { Opportunities to pitch for } \\
\text { new work with other } \\
\text { divisions of Fincorp. }\end{array}$} & $\begin{array}{l}\text { Agency: Positive. A focus on pursuing opportunities to secure } \\
\text { sustainable revenue. Concern emanating from the instability of the } \\
\text { advertising market. }\end{array}$ \\
\hline & $\begin{array}{l}\text { Bank: Hesitant. Concern about short term capacity issues. Emphasis } \\
\text { on fulfilling 'primary duties' (Account Manager) over pursuing } \\
\text { additional work. }\end{array}$ \\
\hline \multirow[t]{2}{*}{$\begin{array}{l}\text { Discussions regarding use } \\
\text { of office space. Frequent } \\
\text { and ongoing discussion } \\
\text { about greater physical } \\
\text { integration with Fincorp. }\end{array}$} & $\begin{array}{l}\text { Agency: Resistant. Focus on maintaining creative independence and } \\
\text { maintaining the distinct reputation of the agency. Concern that greater } \\
\text { integration would undermine the value of Creative Hub as a source of } \\
\text { external expertise. }\end{array}$ \\
\hline & $\begin{array}{l}\text { Bank: Positive. Focus on an anticipated increase in responsiveness, a } \\
\text { better understanding of the needs of Fincorp, and greater ability to } \\
\text { deliver on }\end{array}$ \\
\hline
\end{tabular}


Table 3: Ongoing Intra-Paradigm Tensions

\begin{tabular}{|c|c|c|c|}
\hline Ongoing Topic & Response & Temporal Depth & Temporal Horizons \\
\hline \multirow{2}{*}{$\begin{array}{l}\text { Discussions } \\
\text { regarding recruiting } \\
\text { high profile } \\
\text { candidates for the } \\
\text { creative team. }\end{array}$} & $\begin{array}{l}\text { Agency: Broadly positive. Emphasis on the } \\
\text { reputational gains that would raise the profile of } \\
\text { Creative Hub. Prospect of further recognition through } \\
\text { industry awards. }\end{array}$ & $\begin{array}{l}\text { Agency: Long and ill-defined. Focus on } \\
\text { improved reputation at an undefined point in the } \\
\text { future. }\end{array}$ & $\begin{array}{l}\text { Agency: Irregular, infrequent. Markers } \\
\text { for gains are loosely-defined and } \\
\text { irregular. Including: positive press, } \\
\text { awards, positive word-of-mouth. }\end{array}$ \\
\hline & $\begin{array}{l}\text { Bank: Hesitant. Discussions cited the expense and } \\
\text { the issue of efficiency in the annual reports. Emphasis } \\
\text { on getting better value for money. }\end{array}$ & $\begin{array}{l}\text { Bank: Short. References to budgetary concerns } \\
\text { were made with reference to quarterly financial } \\
\text { review. }\end{array}$ & $\begin{array}{l}\text { Bank: Regular and frequent. Clearly } \\
\text { defined reporting cycles at short } \\
\text { quarterly intervals. }\end{array}$ \\
\hline \multirow{2}{*}{$\begin{array}{l}\text { Opportunities to } \\
\text { pitch for new work } \\
\text { with other divisions } \\
\text { of Fincorp. }\end{array}$} & $\begin{array}{l}\text { Agency: Enthusiastic. A focus on pursuing } \\
\text { opportunities to secure sustainable revenue. Concern } \\
\text { emanating from the instability of the sector. }\end{array}$ & $\begin{array}{l}\text { Agency: Medium to Long. Focus on sustained } \\
\text { growth and alternative sources for funding if } \\
\text { existing contracts are reduced in future years. }\end{array}$ & $\begin{array}{l}\text { Agency: Infrequent. Belief that most } \\
\text { client-contracts are stable for 'a few } \\
\text { years' Account Director. }\end{array}$ \\
\hline & $\begin{array}{l}\text { Bank: Hesitant. Concern about short term capacity } \\
\text { issues. Emphasis on fulfilling 'primary duties' } \\
\text { (Account Manager) over pursuing additional work. }\end{array}$ & $\begin{array}{l}\text { Bank: Very short. Capacity concerns were } \\
\text { voiced regarding the present and immediate } \\
\text { future. Fears that existing projects couldn't be } \\
\text { fulfilled if staff worked on pitch. }\end{array}$ & $\begin{array}{l}\text { Bank: Frequent. All existing projects } \\
\text { had short intervals and regular project } \\
\text { check-ins. }\end{array}$ \\
\hline \multirow{2}{*}{$\begin{array}{l}\text { Discussions } \\
\text { regarding use of } \\
\text { office space. } \\
\text { Frequent and } \\
\text { ongoing discussion } \\
\text { about greater } \\
\text { physical integration } \\
\text { with Fincorp. }\end{array}$} & $\begin{array}{l}\text { Agency: Resistant. Focus on maintaining creative } \\
\text { independence and maintaining the distinct reputation } \\
\text { of the agency. Concern that greater integration would } \\
\text { undermine the value of Creative Hub as a source of } \\
\text { external expertise. }\end{array}$ & $\begin{array}{l}\text { Agency: Long and ill-defined. Concern } \\
\text { regarding image and identity of the organization. } \\
\text { Belief that Creative Hub must visibly remain 'to } \\
\text { some degree' (Planner) independent and external } \\
\text { to nurture this. }\end{array}$ & $\begin{array}{l}\text { Agency: Irregular. Horizons are not } \\
\text { clearly defined. Identity and } \\
\text { reputational factors referred to during } \\
\text { pitches, recruitment and award season. }\end{array}$ \\
\hline & $\begin{array}{l}\text { Bank: Positive. Focus on an anticipated increase in } \\
\text { responsiveness, a better understanding of the needs of } \\
\text { Fincorp, and greater ability to deliver on }\end{array}$ & $\begin{array}{l}\text { Bank: Short. Focus on efficiencies and positive } \\
\text { reviews in in quarterly and annual reporting. }\end{array}$ & $\begin{array}{l}\text { Bank: Regular. Focus on improved } \\
\text { reviews from Fincorp in quarterly and } \\
\text { annual reports. }\end{array}$ \\
\hline
\end{tabular}


Figure 1: Interplay of Temporal Structures

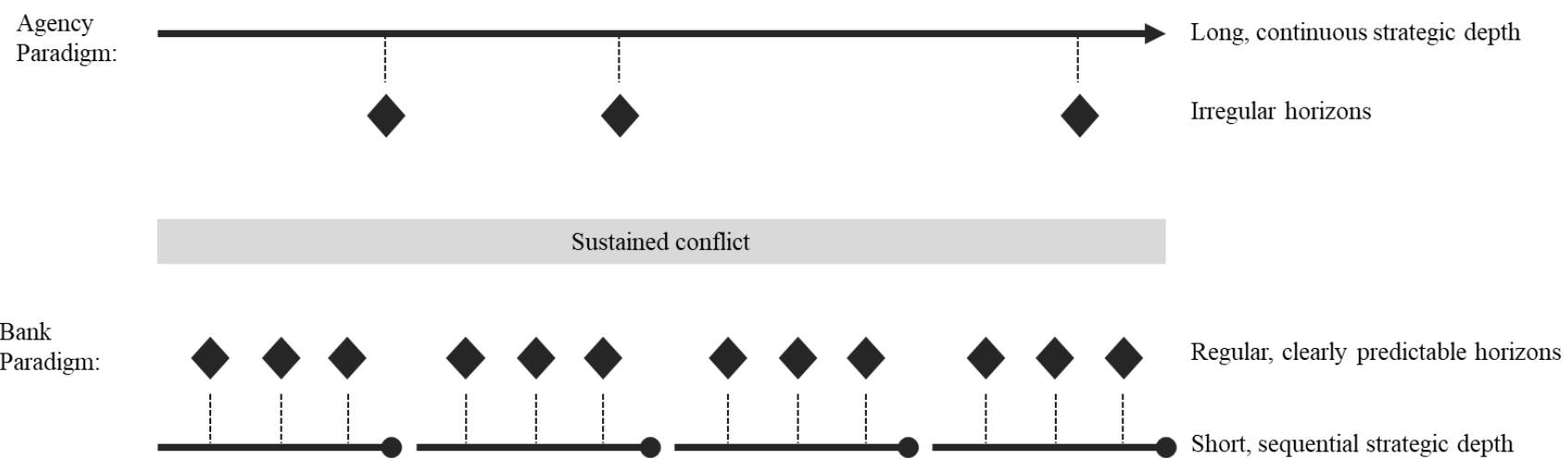

Figure 2: Interplay of Distinct Horizons with renegotiated Temporal Depth

Agency

Paradigm:

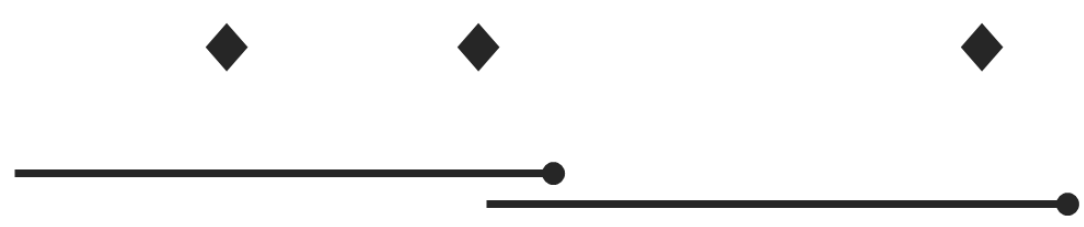

Irregular horizons fit within revised depth

Shared Temporal Depth: Defined, medium length.

Bank

Paradigm:

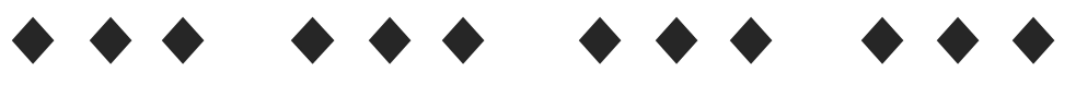

Regular horizons building to defined depth 
Table 3: Application of revised Temporal Depth to Ongoing Discussions

\begin{tabular}{|c|c|c|c|}
\hline Ongoing Topic & $\begin{array}{l}\text { Temporal } \\
\text { Depth }\end{array}$ & Temporal Horizons & Settlement \\
\hline \multirow{2}{*}{$\begin{array}{l}\text { Discussions regarding } \\
\text { recruiting high profile } \\
\text { candidates for the } \\
\text { creative team. }\end{array}$} & \multirow{6}{*}{$\begin{array}{l}\text { Tightly } \\
\text { defined, shared } \\
\text { temporal depth } \\
\text { of two years. }\end{array}$} & $\begin{array}{l}\text { Agency: Irregular, infrequent. Markers for gains are } \\
\text { loosely-defined and irregular. Including: positive } \\
\text { press, awards, positive word-of-mouth. }\end{array}$ & \multirow{2}{*}{$\begin{array}{l}\text { Concession that any hire needs to represent 'value for } \\
\text { money' in the space of two years. Recognition that a } \\
\text { senior hire would represent an investment. Recruitment } \\
\text { moves from 'high profile' to 'experienced' hires with } \\
\text { additional responsibilities. }\end{array}$} \\
\hline & & $\begin{array}{l}\text { Bank: Regular and frequent. Clearly defined } \\
\text { reporting cycles at short quarterly intervals. }\end{array}$ & \\
\hline \multirow{2}{*}{$\begin{array}{l}\text { Opportunities to pitch } \\
\text { for new work with other } \\
\text { divisions of Fincorp. }\end{array}$} & & $\begin{array}{l}\text { Agency: Infrequent. Belief that most client-contracts } \\
\text { are stable for 'a few years' Account Director. }\end{array}$ & \multirow{2}{*}{$\begin{array}{l}\text { Ambition to jointly pursue new business pitches without } \\
\text { compromising existing projects. Efforts include } \\
\text { increasing capacity by hiring short-term freelancers and } \\
\text { developing workflow plans that create sufficient slack } \\
\text { for new }\end{array}$} \\
\hline & & $\begin{array}{l}\text { Bank: Frequent. All existing projects had short } \\
\text { intervals and regular project check-ins. }\end{array}$ & \\
\hline \multirow{2}{*}{$\begin{array}{l}\text { Discussions regarding } \\
\text { use of office space. } \\
\text { Frequent and ongoing } \\
\text { discussion about greater } \\
\text { physical integration } \\
\text { with Fincorp. }\end{array}$} & & $\begin{array}{l}\text { Agency: Irregular. Horizons are not clearly defined. } \\
\text { Identity and reputational factors referred to during } \\
\text { pitches, recruitment and award season. }\end{array}$ & \multirow{2}{*}{$\begin{array}{l}\text { Movement from physically integrating Creative Hub } \\
\text { within the Fincorp marketing team to maintaining } \\
\text { separate space while increasing perceived integration. } \\
\text { Steps taken include account managers working in } \\
\text { Fincorp marketing teams and secondments from } \\
\text { Creative Hub to Fincorp. }\end{array}$} \\
\hline & & $\begin{array}{l}\text { Bank: Regular. Focus on improved reviews from } \\
\text { Fincorp in quarterly and annual reports. }\end{array}$ & \\
\hline
\end{tabular}




\section{REFERENCES}

Amason, A., (1996). Distinguishing the Effects of Functional and Dysfunctional Conflict on Strategic Decision Making: Resolving a Paradox for Top Management Teams. Academy of Management Journal, 39(1), 123-148.

Ancona, D., Goodman, P., Lawrence, B. and Tushman, M., (2001). Time: A New Research Lens. The Academy of Management Review, 26(4), 645-663.

Battilana, J. and Dorado, S., (2010). Building Sustainable Hybrid Organizations: The Case of Commercial Microfinance Organizations. Academy of Management Journal, 53(6), 1419-1440.

Bednarek R, Paroutis S and Sillince J., (2016). Transcendence through rhetorical practices: Responding to paradox in the science sector. Organization Studies 38(1): 77-101.

Berends, H. and Deken, F., (2019). Composing qualitative process research. Strategic Organization, $0(0) 1-13$.

Blumer, H. (1954) What is wrong with social theory?. American Sociological Review, 19(1): 3-10.

Bluedorn, A.C. (2002) The Human Organization of Time: Temporal Realities and Experience. Stanford, CA: Stanford University Press

Bluedorn, A.C., and Martin, G., (2006) The time frames of entrepreneurs. Journal of Business Venturing 23(1): $1-20$

Bluedorn, A.C. and Standifer, R.L. (2006) Time and the temporal imagination. Academy of Management Learning \& Education, 5, 196-206.

Brown, T., Dacin, P., Pratt, M., and Whetten, D. (2006) 'Identity, Intended Image, Construed Image, And Reputation: An Interdisciplinary Framework and Suggested Terminology'. Journal of the Academy of Marketing Science, 34(2), 99-106

Cameron, K. S., \& Quinn, R. E. (1988). Organizational paradox and transformation. In Quinn, R. E., \& Cameron, K. S. (Eds.), Paradox and transformation: Toward a theory of change in organization and management: 12-18. Cambridge, MA: Ballinger.

Chen, M. and Miller, D., (2011). The Relational Perspective as a Business Mindset: Managerial Implications for East and West. Academy of Management Perspectives, 25(3), 6-18.

Chen, J., Miller, D. and Chen, M., (2019). Top management team time horizon blending and organizational ambidexterity. Strategic Organization, 0(0) 1-24

Chen, J., \& Nadkarni, S. (2017). It's about time! CEOs' temporal dispositions, temporal leadership, and corporate entrepreneurship. Administrative Science Quarterly, 61(1), 31e66

Cialdini, R., Trost, M. and Newsom, J., (1995). Preference for consistency: The development of a valid measure and the discovery of surprising behavioral implications. Journal of Personality and Social Psychology, 69(2), 318-328.

Clegg, S., da Cunha, J. and e Cunha, M., (2002). Management Paradoxes: A Relational View. Human Relations, 55(5), 483-503.

Das, T.K. (1987). Strategic planning and individual temporal orientation. Strategic Management Journal 8(2), 203-209. 
Dawson, P. (2014). Reflections: On time, Temporality and Change in Organizations, Journal of Change Management 14(3), 1-24.

Eisenhardt, K. M. (2000). Paradox, spirals, ambivalence: The new language of change and pluralism. Academy of Management Review, 25(1) 703-705.

Farjoun M. (2010). Beyond dualism: Stability and change as a duality. Academy of Management Review 35(2): 202-225

Farjoun, M. (2017). Contradictions, dialectics and paradox. in Langley A. and Tsoukas H. (Ed.), Sage Handbook of Process Organization Studies, London: Sage, 87-109

Gephart, R., (2004). Qualitative Research and the Academy of Management Journal. Academy of Management Journal, 47(4), 454-462.

Gibson, C. and Birkinshaw, J., (2004). The Antecedents, Consequences, and Mediating Role of Organizational Ambidexterity. Academy of Management Journal, 47(2), 209-226.

Gioia, D., Corley, K. G. and Hamilton, A. L., (2012) Seeking Qualitative Rigor in Inductive Research: Notes on the Gioia Methodology. Organizational Research Methods, 16(1), 15-31

Golden-Biddle, K. and Rao, H., (1997). Breaches in the Boardroom: Organizational Identity and Conflicts of Commitment in a Nonprofit Organization. Organization Science, 8(6), 593-611.

Granqvist, N. and Gustafsson, R. (2016), Temporal Institutional Work, Academy of Management Journal, 59(3), 1009-1035.

Greenwood, R., Raynard, M., Kodeih, F., Micelotta, E. and Lounsbury, M., (2011). Institutional Complexity and Organizational Responses. The Academy of Management Annals, 5(1), 317 371.

Hatch, M. J., \& Ehrlich, S. B. (1993). Spontaneous humour as an indicator of paradox and ambiguity in organizations. Organization Studies, 14(4), 505-526.

Hahn, T., Preuss, L., Pinkse, J. and Figge, F., (2014). Cognitive Frames in Corporate Sustainability: Managerial Sensemaking with Paradoxical and Business Case Frames. Academy of Management Review, 39(4), 463-487.

Huy, N. Q., (2001). Time, Temporal Capability, and Planned Change. Academy of Management Review, 26(4), 601-623.

Inkpen, A. and Currall, S., (2004). The Coevolution of Trust, Control, and Learning in Joint Ventures. Organization Science, 15(5), 586-599.

Jarzabkowski, P., Lê, J. and Van de Ven, A., (2013). Responding to competing strategic demands: How organizing, belonging, and performing paradoxes coevolve. Strategic Organization, 11(3), 245280.

Jay, J., (2013). Navigating Paradox as a Mechanism of Change and Innovation in Hybrid Organizations. Academy of Management Journal, 56(1), 137-159.

Jick, T. (1979). Mixing Qualitative and Quantitative Methods: Triangulation in Action. Administrative Science Quarterly, 24(4), 602-611

Kaplan, S., and Orlikowski, W. (2013). Temporal Work in Strategy Making. Organization Science, 24(4), 965-995. 
Kraatz, M. and Block, E., (2008). Organizational Implications of Institutional Pluralism. In Greenwood, R., Oliver C, Sahlin K, et al. (eds). The SAGE Handbook of Organizational Institutionalism. London: SAGE. 243-275.

Kunisch, S., Bartunek, J., Mueller, J. and Huy, Q., (2017). Time in Strategic Change Research. Academy of Management Annals, 11(2), 1005-1064.

Langley, A. (1999). Strategies for theorizing from process data. Academy of Management Review, 24, 691-710

Langley, A., Smallman, C., Tsoukas, H. and Van de Ven, A., (2013). Process Studies of Change in Organization and Management: Unveiling Temporality, Activity, and Flow. Academy of Management Journal, 56(1), 1-13.

Langley A and Tsoukas H (eds.) (2017) The SAGE Handbook of Process Organizational Studies. London: SAGE.

Leana, C. and Barry, B., (2000). Stability and Change as Simultaneous Experiences in Organizational Life. Academy of Management Review, 25(4), 753-759.

Lee, T. W. (1999). Using qualitative methods to organize research. Sage Publications, Thousand Oaks, CA.

Lewis, M., (2000). Exploring Paradox: Toward a More Comprehensive Guide. The Academy of Management Review, 25(4), 760-776.

Lincoln, Y. and Guba, E., (1985). Naturalistic Inquiry. Beverly Hills, Calif: Sage.

Lumpkin, G. and Brigham, K., (2011). Long-Term Orientation and Intertemporal Choice in Family Firms. Entrepreneurship Theory and Practice, 35(6), 1149-1169.

Lüscher, L. and Lewis, M. (2008). Organizational Change and Managerial Sensemaking: Working Through Paradox. Academy of Management Journal, 51(2), 221-240.

Maitlis, S. and Sonenshein, S., (2010). Sensemaking in Crisis and Change: Inspiration and Insights From Weick (1988). Journal of Management Studies, 47(3), 551-580.

Mathias, B., Mckenny, A. and Crook, T., (2018). Managing the tensions between exploration and exploitation: The role of time. Strategic Entrepreneurship Journal, 12(3), 316-334.

Miron-Spektor, E., Ingram, A., Keller, J., Smith, W. and Lewis, M., (2018). Microfoundations of Organizational Paradox: The Problem Is How We Think about the Problem. Academy of Management Journal, 61(1), 26-45.

Nicolini, D. (2009). 'Zooming in and out: Studying practices by switching theoretical lenses and trailing connections'. Organization Studies, 30, 1391-418.

Nicolini, D., (2010). Practice as the Site of Knowing: Insights from the Field of Telemedicine. Organization Science, 22(3), 602-620.

Oborn, E. and Barrett, M. (2020) "Marching to different drum beats: a temporal perspective on coordinating occupational work." Organization Science (forthcoming)

O'Reilly, C. and Tushman, M. (2013). Organizational Ambidexterity: Past, Present, and Future. Academy of Management Perspectives, 27(4), 324-338. 
Orlikowski, W. and Yates, J. (2002). It's About Time: Temporal Structuring in Organizations. Organization Science, 13(6), 684-700.

Operti, E. Y., Lampronti, S. and Sgourev, S., (2020). Hold Your Horses: Temporal Multiplexity and Conflict Moderation in the Palio di Siena (1743-2010). Organization Science, 31(1), 85-102.

Pache, A. and Santos, F., (2010). When Worlds Collide: The Internal Dynamics of Organizational Responses to Conflicting Institutional Demands. Academy of Management Review, 35(3), 455476.

Pettigrew A.M. (1990) Longitudinal field research on change: Theory and Practice. Organization Science 1(3): 267-292.

Poole, M. S., \& Van de Ven, A. H. (1989). Using paradox to build management and organization theories. Academy of Management Review, 14: 562-578.

Reay, T., Zafar, A., Monteiro, P., \& Glaser, V. (2019). Presenting Findings from Qualitative Research: One Size Does Not Fit All!. In Amis, J., Mair, J. and Zilber, T. 'The Production of Managerial Knowledge And Organizational Theory: New Approaches To Writing, Producing And Consuming Theory'. London: Emerald Publishing Limited. 201-216.

Reinecke, J. and Ansari, S. (2015). When Times Collide: temporal brokerage at the intersection of markets and developments. Academy of Management Journal, 58, 618-648.

Rowell, C., Gustafsson, R. and Clemente, M. (2016). How Institutions Matter "In Time": The Temporal Structures of Practices and Their Effects on Practice Reproduction. Research in the Sociology of Organizations, 48(1), 303-327.

Schad, J. and Bansal, P., (2019). Seeing the Forest and the Trees: How a Systems Perspective Informs Paradox Research. Journal of Management Studies, 55(8), 1490-1506.

Schneider, K. J. (1990). The paradoxical self: Toward understanding of our contradictory nature. New York: Insight Books

Schultz, M. and Hernes, T., (2019). Temporal interplay between strategy and identity: Punctuated, subsumed, and sustained modes. Strategic Organization, 18(1), 106-135.

Shipp, A. J., Edwards, J. R., \& Lambert, L. S. (2009). Conceptualization and measurement of temporal focus: The subjective experience of the past, present, and future. Organizational Behavior and Human Decision Processes, 110(1), 1-22.

Shipp, A. J., \& Cole, M. S. (2015). Time in individual-level organizational studies: What is it, how is it used, and why isn't it exploited more often? Annual Review of Organizational Psychology and Organizational Behavior, 2, 237-260

Slawinski, N. and Bansal, P., (2015). Short on Time: Intertemporal Tensions in Business Sustainability. Organization Science, 26(2), 531-549.

Smith, W., Erez, M., Jarvenpaa, S., Lewis, M. and Tracey, P., (2017). Adding Complexity to Theories of Paradox, Tensions, and Dualities of Innovation and Change: Introduction to Organization Studies Special Issue on Paradox, Tensions, and Dualities of Innovation and Change. Organization Studies, 38(3-4), 303-317.

Smith, W. and Lewis, M., (2011). Toward a theory of paradox: a dynamic equilibrium model of organizing. Academy of Management Review, 36(2), 381-403. 
Smith, W. and Tracey, P., (2016). Institutional complexity and paradox theory: Complementarities of competing demands. Strategic Organization, 14(4), 455-466

Smith, W. and Tushman, M., (2005). Managing Strategic Contradictions: A Top Management Model for Managing Innovation Streams. Organization Science, 16(5), 522-536.

Staudenmayer, N., Tyre, M., \& Perlow, L. (2002). Time to Change: Temporal Shifts as Enablers of Organizational Change. Organization Science, 13(5), 583-597.

Tsoukas, H., (2009) A dialogical approach to the creation of new knowledge in organizations, Organization Science, 20(6), 941-957.

Tsoukas, H. (2017). Don't simplify, complexify: From disjunctive to conjunctive theorizing in organization and management studies. Journal of Management Studies, 54(2), 132-153.

Van Maanen, J., (1979). The Fact of Fiction in Organizational Ethnography. Administrative Science Quarterly, 24(4), 539-550.

Vince, R., \& Broussine, M. (1996). Paradox, defense and attachment: Accessing and working with emotions and relations underlying organizational change. Organization Studies, 17(1), 1-21.

Wang, T. and Bansal, P., (2012). Social responsibility in new ventures: profiting from a long-term orientation. Strategic Management Journal, 33(10), 1135-1153.

Webb, E. and Weick, K., (1979). Unobtrusive Measures in Organizational Theory: A Reminder. Administrative Science Quarterly, 24(4), 650-659.

Wiebe, E. (2010). Temporal sensemaking: Managers' use of time to frame organizational change. In T. Hernes and S. Maitlis (Eds.), Process, sensemaking, and organizing (213-241). Oxford: Oxford University Press.

Wood, M., Bakker, R. and Fisher, G. (2019). Back to the future: a time-calibrated theory of entrepreneurial action. Academy of Management Review. Forthcoming.

Ybema, S. (2010). Talk of change: temporal contrasts and collective identities. Organization Studies, 31, 481-503.

Zimbardo, P. G., \& Boyd, J. N. (1999). Putting time in perspective: A valid, reliable individualdifferences metric. Journal of Personality and Social Psychology, 77(6), 1271-1288. 